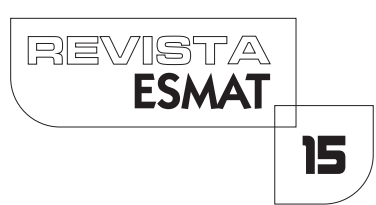

\title{
DERECHOS HUMANOS Y LA ERRADICACIÓN DE LA POBREZA EN MÉXICO
}

HUMAN RIGHTS AND THE ERADICATION OF POVERTY IN MEXICO

Armando Soto Flores

Doctor en Derecho por la UNAM. Profesor de carrera de tiempo completo en las materias de Teoría de la Constitución y Derecho Constitucional. Jefe de la División de Estudios de Posgrado de la UNAM. Investigador Nacional nivel I del CONACYT

\section{RESUMEN}

La pobreza presenta un problema en cuanto a su definición. Los estándares que la catalogan varían de región en región, no obstante, se reconoce que la pobreza es un fenómeno multifactorial que se traduce en la falta de bienes y servicios necesarios para la subsistencia. Los derechos fundamentales que sirven de motor para su erradicación son los clasificados dentro de los derechos económicos, sociales y culturales. Si bien el contenido de estos últimos derechos es contingente, suelen referirse al derecho al trabajo, a la seguridad social, a la vivienda, al medio ambiente sano, a la familia, a la educación, al agua y a la alimentación. El sistema jurídico mexicano cuenta con una doble protección y garantía para este tipo de derechos: a nivel nacional, los artículos 4, 5 y I 23 constitucionales los reconocen y los garantizan mediante el juicio de amparo; y en materia internacional, México suscribió la Convención Americana sobre Derechos Humanos y el Protocolo de San Salvador -mismo que regula los derechos económicos, sociales y culturales_-, los cuales encuentran garantía en los procedimientos previstos dentro del Sistema Interamericano de los Derechos Humanos.

PALABRAS CLAVE: Erradicación de la pobreza; pobreza en México; juicio de amparo; derechos humanos en México; México; derechos económicos, sociales y culturales; Protocolo de San Salvador; Constitución Mexicana.

\section{ABSTRACT}

Poverty presents a problem in terms of its definition. The standards that measure it vary from region to region. However, poverty is a multifactorial phenomenon that translates 
into the lack of goods and services necessary for subsistence. The fundamental rights that serve to eradicate poverty are classified within economic, social and cultural rights. They usually refer to the right to work, social security, housing, a healthy environment, family, education, water and food. The Mexican legal system has a double protection and guarantee for this type of rights: in the national law, constitutional articles 4, 5 and 123 recognize them and guarantee them through the 'amparo' figure; while in international law, Mexico signed the American Convention on Human Rights and the Protocol of San Salvador, which regulates economic, social and cultural rights. These are guaranteed by the procedures provided for at the Inter-American Human Rights System.

KEYWORDS: Poverty eradication; poverty in Mexico; Mexican human rights; Mexico; economic, social and cultural rights; Protocol of San Salvador; Mexican constitution.

\section{INTRODUCCIÓN}

\section{Generalidades}

El título de la norma suprema que crea el sistema jurídico mexicano es el de Constitución Política de los Estados Unidos Mexicanos. Este último es, precisamente, el nombre oficial del país que limita al norte con los Estados Unidos de América y al sur con Guatemalay Belice.

Si bien el nombre oficial se asemeja a nuestro vecino del norte, este mote sólo se ha aplicado a partir de 1917, fecha en que entró en vigor nuestra constitución actual. Anteriormente, nuestro país había tenido diferentes denominaciones.

Desde la llegada de los conquistadores españoles a territorio nacional, en el año I5 I9, hasta I 8 I 4 se conoció con el nombre de Virreinato de la Nueva España a nuestro territorio; y por primera vez, la palabra México apareció en los anales de la historia para nombrar a la antigua Tenochtitlán.

Su etimología viene de la denominación que los aztecas se daban a sí mismos: mexicas; que tendría sus orígenes en Mexi, nombre del sacerdote que habría conducido a los aztecas hasta la cuenca del Valle de México y, según la leyenda, habría encontrado un águila posada sobre un nopal devorando a una serpiente.

A la postre, la capital del virreinato legaría su denominación al territorio nacional. El primero en llamar México a la Nueva España fue José María Morelos y Pavón, insurgente mexicano quien en 1813 convocó al primer congreso constituyente, mismo que habría de promulgar el Decreto constitucional para la América Mexicana en I 8 | 4.

A partir de ese momento, todos los documentos constitucionales retomarían el nombre de México, por esa razón suele conocerse más a nuestro país por esa forma, más que por la oficial.

Territorialmente, México ocupa un total de I,964,375 km², siendo el decimocuarto país más grande del mundo. La constitución mexicana de 1917 define a los Estados 
Unidos Mexicanos como una república, democrática, representativa y federal, compuesta por treinta y dos estados federados, incluyendo la Ciudad de México, la cual es, a partir del 29 de enero del 2016 , el estado más nuevo de la federación.

La Encuesta Intercensal del $2015^{\prime}$ arrojó que México contaba con una población de I 19.5 millones de habitantes, aunque las estimaciones para este año aseguran que habemos 123.5 millones de mexicanos ${ }^{2}$. Esta cifra nos coloca como el país de habla española más poblado del planeta.

De esos 123.5 millones de habitantes, cerca del $51 \%$ son mujeres, mientras que el 49\% restante, son hombres. Del análisis de la tasa de natalidad y mortandad del Instituto Nacional de Estadística y Geografía (INEGI), por cada minuto que pasa nacen cinco mexicanos, mientras que uno muere.

La esperanza de vida en México hoy en día es de 75 años. Del $100 \%$ de la población el $27 \%$ son niños entre los 0 y los 14 años de edad; el 26\% jóvenes entre los 15 y 29 años; el 36\% adultos entre los 30 y 59 años; y sólo el I I\% lo componen adultos mayores de más de 60 años de edad.

De esos 123 millones y medio de personas el 89\% de ellas habla español y/u otras lenguas no vernáculas; sólo un 5\% de la población es bilingüe, entendiendo que es capaz de comunicarse en español y en otra lengua indígena; y el 1\% habla alguna de las 67 lenguas indígenas, sin comprender el español.

En relación a los hogares mexicanos, el $89 \%$ los conforman familias, en tanto que el I 1 \% restante son no familiares, es decir, que están conformados por vínculos distintos, como lo son entre amigos, etc. De la totalidad, en el 29\% de los hogares el responsable de la familia es una mujer.

De los 123 millones y medio de mexicanos, el 17\% de ellos son niños entre 6 y 14 años. De ese porcentaje, sólo un $16 \%$ de los niños asisten a la escuela. La población que se encuentra en edad escolar, se reparte de la siguiente manera: el 4\% no tiene estudios de ningún tipo; el 39\% cursa la educación básica; el 16\% está inscrito en algún programa de educación media superior; y el I 4\% se encuentra cursando algún plan o programa en instituciones de educación superior.

En lo que respecta a la ocupación laboral, el 78\% de la población tiene doce años o más. Mientras que un 39\% cuenta con empleo; otro 39\% se reparte entre: estudiantes ( $12 \%)$; trabajadores domésticos ( $18 \%)$; jubilados (2\%); quienes realizan otra actividad (5\%); y personas con alguna discapacidad ( $1 \%)$.

'Cfr. http://www.beta.inegi.org.mx/proyectos/enchogares/especiales/intercensal/default.html

2 "México cuenta con 123.5 millones de habitantes", El Economista, versión electrónica del 10 de julio del 2017, consultado en http://eleconomista.com.mx/sociedad/2017/07/10/mexicocuenta- | 235-millones-habitantes el día 28 de septiembre del 2017. 
De los $39 \%$ que cuentan con un empleo, el $4 \%$ se desempeña en el sector primario (actividades como la agricultura y la ganadería); el I $0 \%$ realiza sus actividades en el sector secundario (industria extractiva, generación de electricidad, transformación y construcción); y el resto del $25 \%$ se dedica al sector terciario o de bienes y servicios.

De esos mismos 39\%, el II\% percibe de tres o más salarios mínimos -el equivalente aproximado a 13 dólares diarios_; el 8\% recibe de 2 a 3 salarios mínimos -entre 8.69 a 13 dólares diarios-; el 13\% gana por sus actividades menos de dos salarios mínimos; y el uno por ciento no tiene ningún tipo de ingreso.

Los indicadores de vivienda del INEGI reportan que el $77 \%$ de los mexicanos viven en localidades de 2,500 personas o más; mientras el $23 \%$ habita en pequeñas comunidades. De la totalidad de viviendas censadas, el $4 \%$ cuenta con piso de tierra; el 95\% recibe agua entubada; el 99\% tiene electricidad; el 33\% de las casas cuenta por lo menos con una computadora; el $85 \%$ con refrigerador; y el $93 \%$ con televisión.

México es catalogado como un Estado con un Índice de Desarrollo Humano alto ${ }^{3}$, colocándose en el lugar 77. A pesar de ello, los niveles de pobreza son preocupantes. El Consejo Nacional de Evaluación de la Política de Desarrollo Social, el organismo encargado de medir la pobreza en México, determinó que el $43.6 \%$ de los mexicanos padecen algún tipo de pobreza; y el 7.6\% del total, pobreza extrema. Lo anterior refleja un Estado cuya riqueza está mal distribuida, y con índices muy elevados de corrupción, pues es considerado el país más corrupto de la Organización para la Cooperación y el Desarrollo Económico (OCDE). ${ }^{4}$ Según el Índice de Percepción de Corrupción ${ }^{5}$ de Transparencia Internacional en el año 20 I 6, la nación mexicana ocupó el puesto I 23 de 176 Estados.

"Venezuela -señala el reporte del informe — con una puntuación de 17, es quien tiene el puntaje más bajo en la región. El año pasado se vieron cientos de miles de ciudadanos protestando contra el gobierno. En México, mientras el gobierno intenta limpiar la imagen del país mediante una serie de reformas, los escándalos de corrupción continúan escalando y la tasa de aprobación del presidente está más baja que nunca."

La corrupción junto con una repartición de la riqueza desigual, provoca un efecto nocivo para la sociedad mexicana: la impunidad.

\footnotetext{
${ }^{3}$ Panorama general. Informe sobre desarrollo humano 2016. Desarrollo humano para todos, Programa de las Naciones Unidas para el Desarrollo, Nueva York 20 I 6, p. 23.

${ }^{4}$ Cfr. "México, más corrupto entre países de OCDE", "El Universal", consultado en http://www.eluniversal.com.mx/articulo/nacion/politica/2017/01/12/mexico-mas-corruptoentre-paises-de-ocde el día 28 de septiembre del 2016.

${ }^{5}$ Cfr. https://www.transparency.org/news/feature/corruption_perceptions_index_2016\#table, consultado el día 29 de septiembre del 2017.

${ }^{6}$ Ídem.
} 
La Encuesta Nacional de Victimización y Percepción sobre Seguridad Pública 2016 (ENVIPE) ${ }^{7}$ estima que el 34\% de los hogares en el país fueron víctimas de algún delito. Asimismo, determinó que 23.3 millones de personas, de 18 años o más, fueron víctimas de alguna conducta delictiva, lo que equivale a una tasa de 28,202 víctimas por cada cien mil habitantes durante 2015. Los delitos que más padece la sociedad mexicana son el robo, en sus distintas modalidades, y la extorsión.

Los costos de la delincuencia en México son abismales, la encuesta en comento estimó que para el 2015, el costo total a consecuencia de la inseguridad y el delito en hogares representó un monto de 236.8 mil millones de pesos, el equivalente a casi 13 mil millones de dólares, lo que representa el I.25\% del Producto Interno Bruto.

La cifra negra que muestra la ENVIPE, es que durante el 2015 se denunciaron ante la autoridad investigadora sólo el 6.3\% de los delitos cometidos; es decir, más del 93.7\% de los hechos ilícitos quedaron impunes. De ese ínfimo 6.3\%, en menos de la mitad (45.9\%) no se realizó ninguna acción por parte de la autoridad. Según el propio Instituto Nacional de Estadística y Geografía, sólo cerca del 10\% de los delitos denunciados, terminan en sentencia condenatoria; lo que equivale a decir, que, por desgracia, al día de hoy, en México hay una impunidad que roza el I00\%.

Ante este panorama tan negro sólo queda hacerse una pregunta: ¿qué solución tomar? Las respuestas necesariamente son varias, pues las causas que producen todos esos efectos son diversas. La materia jurídica es el punto de análisis del presente trabajo, y cabe cuestionarse: ¿cómo el Derecho puede coadyuvar con otras soluciones a un problema social tan complejo?

La Encuesta Nacional de Victimización y Percepción sobre Seguridad Pública 2016 muestra que entre las razones de las víctimas para no denunciar delitos ante las autoridades destacan la "pérdida de tiempo", con un 33\%, y la "desconfianza en la autoridad" con un 16.6\%."

Del $63 \%$ de los delitos que no fueron presentados, se debieron a la desconfianza existente ante las autoridades convencionales. Derivados de los resultados arrojados de la Encuesta Nacional en Viviendas", realizada por Consultas Mitofsky para el periódico "El Economista", se desprende que las instituciones con las que cuentan el mayor número de confianza para los mexicanos son: las universidades, la iglesia, el ejército y la Comisión Nacional de los Derechos Humanos.

${ }^{7}$ Cfr. Presentación nacional de la Encuesta Nacional de Victimización y Percepción sobre Seguridad Pública 2016.

${ }^{8}$ Ídem.

9 Encuesta Nacional en Viviendas, Consulta Mitofsky, octubre del 2016, consultado en http://www.consulta.mx/index.php/estudios-e-investigaciones/mexico-opina/item/884-mexicoconfianza-en-instituciones-2016 el día 29 de septiembre del 2017. 
De estas cuatro últimas, la única institución gubernamental—sin por ello menospreciar a las universidades públicas — capaz de generar un cambio profundo en la sociedad mediante el Derecho, es la Comisión Nacional de los Derechos Humanos.

Resulta, pues, importante realizar un estudio a profundidad sobre cómo operan los derechos fundamentales en México y, sobre todo, cómo son capaces, en su correcta aplicación, de constituirse en un motor que comience a funcionar y produzca cambios en los otros factores que tienen a México en su situación actual.

\section{Derechos Humanos y Derechos Fundamentales}

El término de "derechos humanos" es más bien reciente. A pesar de que las teorías más vanguardistas equiparan el reconocimiento de los derechos de libertad (siglo XVIII) y derechos políticos (a partir de la Revolución Francesa) como la primera y segunda generación de los derechos humanos respectivamente; lo cierto es que este término fue empleado con regularidad hasta la segunda mitad del siglo $X X$.

La expresión "derechos humanos" tiene un amplio campo de estudio. Puede ser analizado por diversas disciplinas; hay "derechos humanos" en la Filosofía, en concreto en la Teoría de la Justicia y la Filosofía Política. Para estas disciplinas "lo importante es explicar la corrección de que ciertos valores sean recogidos por el derecho positivo en cuanto derechos fundamentales, así como justiciar la necesidad de incorporar como derechos nuevas expectativas o aspiraciones de las personas y grupos que conviven en sociedad"'

En sociología también aparecen los derechos humanos, en cuyo caso trata "de estudiar el grado de eficacia que los derechos han tenido y tienen en la realidad, así como los factores que inciden en esa eficacia, los grupos sociales que presionan para que se creen nuevos derechos o aquellos que se oponen a los ya consagrados."

Pues bien, la dogmática jurídica considera denominar a los derechos humanos como derechos fundamentales, reconociendo que éstos están "consagrados en los textos constitucionales o en algunos tratados internacionales." "Y $Y$ en términos generales puede decirse que los derechos fundamentales son considerados como tales en la medida en que constituyen instrumentos de protección a los intereses más importantes de las personas, puesto que preservan los bienes básicos necesarios para poder desarrollar cualquier plan de vida de manera digna." '3

\footnotetext{
${ }^{10}$ Carbonell Sánchez, Miguel, Los derechos fundamentales en México, Editorial Porrúa, México 2009 , p. 3.

"Ibidem, p. 4.

${ }^{12}$ Ibidem, p. 3.

${ }^{13}$ Ibidem, p. 5.
} 
En Derecho, por tanto, toca hablar de derechos fundamentales, cuya función histórica reside en dos ejes: como medios de control de la convencionalidad, pues limitan el poder del soberano; y como garantes del mínimo para todo ser humano.

En el caso mexicano, la historia de estos derechos fundamentales es larga, aunque no por ello interesante. México se honra al contar con la primera constitución social de la historia del orbe; y en ella, treinta años antes de siquiera hablar de derechos humanos, se regularon prerrogativas fundamentales para todo individuo que pisara tierras aztecas.

Para entender la perspectiva de los derechos fundamentales en México, al día de hoy, es necesario hacer un breve recorrido en los textos constitucionales que han regido a nuestro país. Sólo así podrá proyectarse una visión hacia el futuro del llamado "neoconstitucionalismo mexicano".

\section{LOS DERECHOS FUNDAMENTALES EN EL DERECHO CONSTITUCIONAL MEXICANO}

\section{Antecedentes constitucionales}

Los europeos llegaron a tierras continentales mexicanas desde el año | 5 | 7. Tras dos expediciones rechazadas por los mayas en 1517 y 1518, Hernán Cortés desembarcó en el Golfo de México, fundando la primera ciudad española en la América mexicana. Nombró al puerto como "Villa Rica de la Vera Cruz", y continuó su campaña hacia el centro del país.

Después de dos años de arduas luchas, la capital azteca, Tenochtitlán, sucumbió ante la corona española. Ese hecho marca en la historiografía mexicana el fin de época precolombina y el advenimiento de la "colonia".

México quedó comprendido en el Virreinato de la Nueva España, que en el momento de mayor expansión comprendía los actuales territorios de California, Nevada, Colorado, Utah, Nuevo México, Arizona, Texas, Oregón, Washington, Florida y partes de Idaho, Montana, Wyoming, Kansas, Oklahoma y Luisiana, por parte de los actuales Estados Unidos de América. Asimismo, hacían parte del virreinato el suroeste de la actual Columbia Británica de Canadá, la Capitanía General de Guatemala (que comprendía Guatemala, Belice, El Salvador, Honduras, Nicaragua y Costa Rica); la Capitanía General de Cuba (que comprendía la parte insular, actuales Cuba, República Dominicana, Puerto Rico, Guadalupe y Trinidad y Tobago); y la Capitanía General de las Filipinas (actual archipiélago filipino, las islas Carolinas y las Marianas).

La capital virreinal fue la Ciudad de México, y mantuvo, con pocas modificaciones a lo largo de los tres siglos coloniales, el territorio antes descrito.

La situación en la colonia cambió con la introducción de las Reformas Borbónicas a mediados del siglo XVIII. Las innovaciones que planteaban la nueva casa gobernante en Madrid, causaron revuelo en las colonias, y la Nueva España no fue la excepción.

Sin embargo, lo que detonó la inestabilidad total, fue la invasión de Napoleón 
Bonaparte al Imperio Español en I808. En ese momento se discutió en el seno de la colonia, la necesidad de independizarse temporalmente de la corona española, con tal de evitar que fueran anexionados a Francia.

Con ese ideal de autonomía nació el movimiento independentista en México. Y así la madrugada del 16 de septiembre de 1810, un párroco llamado Miguel Hidalgo y Costilla, enarbolando un estandarte con la Virgen de Guadalupe, inició el movimiento armado en la localidad de Dolores.

En un inicio tuvo triunfos importantes en la región central, y habiendo obtenido decisivas victorias, proclamó la proscripción de la esclavitud. Tras una serie de derrotas, Hidalgo fue hecho prisionero y fusilado.

La lucha la continuó un antiguo alumno suyo, José María Morelos y Pavón, quien fue el primero en cambiar el objetivo final de la guerra hacia una independencia total.

En España, mientras tanto, la población comenzó a organizarse para repeler el reino de los Bonaparte. En un primer momento, la población se organizó en forma de juntas locales. Posteriormente, las principales juntas de defensa convocaron a una Junta Central Suprema Gubernativa del Reino para definir la defensa integral del territorio. Ante las sucesivas derrotas españolas por la pésima organización de ésta, la Junta sería disuelta y el gobierno recaería en un consejo de regencia, cuyos cinco integrantes convocarían a Cortes Generales, instalándose en la ciudad de Cádiz en 1812.

A las Cortes fueron convocados representantes de todos los reinos de la corona, equiparando a cada uno de los virreinatos como tales. De esa forma, el 19 de marzo de 18 | 2, las Cortes decidieron promulgar la Constitución Política de la Monarquía Española.

Como tal, esta constitución, también conocida como la Constitución de Cádiz, fue el primer texto constitucional que rigió en la Nueva España. Haciendo un análisis de ella, la Constitución Política de la Monarquía Española se componía de diez títulos divididos en 384 artículos. Se enfoca en organizar el nuevo Estado que pretendía crear, dejando a un lado algún tipo de "Preámbulo" o Declaración de Derechos del Hombre y del Ciudadano, como aparecen en su antecedente más inmediato.

Sin embargo, hay rastros de lo que actualmente se reconoce como derechos fundamentales. El título VII que lleva por nombre "De las contribuciones", el artículo 339 dice a la letra que "Las contribuciones se repartirán entre todos los españoles con proporción a sus facultades, sin excepción ni privilegio alguno." Podría considerarse germen de los principios de equidad y proporcionalidad que operan en materia tributaria.

Llama la atención, asimismo, el título IX, con nombre "De la instrucción pública". En los seis artículos que lo constituyen, su redacción rompe un paradigma de la ciencia jurídica y política. Anteriormente, las redacciones constitucionales implicaban la sujeción del súbdito hacia el Estado. Esa idea prevalece en la mayoría del capitulado de la Constitución de Cádiz; no obstante, tratándose cinco de estos seis artículos -pues el artículo 37l, que cierra el título, propiamente regula la libertad de expresión y de imprenta — el Estado queda obligado hacia sus súbditos, pues se establece la necesidad de que éste establezca escuelas de primeras letras y universidades (art. 366 y 367), 
mismas que contarán con planes de estudios únicos para todo el Imperio (art. 368).

Por el inicio de la Guerra de Independencia en 1810 , la Constitución de Cádiz pasó prácticamente desapercibida en las colonias, aunque constituyó un antecedente fundamental pues devino en fuente histórica de los nuevos textos constitucionales que en la América española habrían de escribirse.

A la par que los liberales españoles luchaban por mantener en pie la Carta Magna, en la Nueva España, al morir Hidalgo, Morelos tomó la bandera de la gesta. Habiendo cosechado victorias y controlado parte del sureste mexicano, decidió convocar el 14 de septiembre de 1813 al Primer Congreso Mexicano que habría de proclamar formalmente su independencia, y en el cual, estaban representantes de todas las provincias del país.

El 22 de octubre de 1814 se promulgó la primera Carta Magna del México republicano, con el título de Decreto constitucional para la libertad de la América Mexicana. "Los constituyentes de Chilpancingo, al igual que los de Cádiz, habían bebido en la misma fuente: tomaron como modelo la asamblea francesa y las constituciones de 1793 y 1795; ello le daba al texto de Apatzingán cierta similitud, en los propósitos y formas establecidas, con la de Cádiz: ambas se basan en el más moderno sentimiento liberal de la época." ${ }^{\prime 4}$

Había, sin embargo, un cambio muy importante en este primer Decreto constitucional: la constitución dedicaba un capítulo entero ${ }^{15}$ al enunciado de "derechos mínimos" de todos los ciudadanos.

El artículo 24 recogía un principio que retomaba de la Declaración de Independencia de las Trece Colonias: el derecho a la felicidad; entendido éste como "el goce de la igualdad, seguridad, propiedad y libertad." 16

Asimismo, fijaba los derechos de presunción de inocencia (art. 30), de audiencia (art. 3 I), de inviolabilidad del hogar (art. 32), de la propiedad (art. 34); del derecho contra actos privativos (art. 35); la libertad de ejercer cualquier cultura, oficio o comercio (art. 38); y tal como lo hacía la Constitución de Cádiz, reconocía el derecho a recibir la instrucción pública, por parte del Estado, y el derecho a la libre expresión e imprenta, en sus artículos 39 y 40 respectivamente.

Esta Constitución por ser redactada en Apatzingán, recibió el apellido de la ciudad que la vio nacer. Aunque constituye el primer ejercicio constitucional en México, se queda lejos de devenir en la primera constitución mexicana; pues las zonas a las que aplicó únicamente fueron aquellas ocupadas por el ejército insurgente.

\footnotetext{
${ }^{14}$ Calzada Padrón, Feliciano, Derecho constitucional, Editorial Porrúa, México 2009, p. 54.

${ }^{15}$ Capítulo V de la Primera Parte, del artículo 24 al 40.

${ }^{16}$ Artículo 24 del Decreto constitucional para la América Mexicana.
} 
Lo cierto es que, al ser capturado Morelos y Pavón, excomulgado y fusilado, la Guerra de Independencia pareció no tener un rumbo fijo. Hubo una ausencia de una figura sólida que liderara la insurgencia. El caudillo que perduró fue Vicente Guerrero, quien se enfrascaría en una guerra de guerrillas contra el ejército realista liderado por Agustín de lturbide.

Tras una negociación entre ambos líderes, en el conocido Plan de Iguala, ambos reconocen la necesidad de la independencia de España. Poco después de la fusión de ambos ejércitos en el Ejército Trigarante en I821, llegó desde la metrópoli el último gobernador de la Nueva España, Juan O' Donojú, quien se entrevistó en la Villa de Córdoba, Veracruz, el 24 de agosto de I 82I con Agustín de Iturbide. Derivado de esa reunión, se suscribió el Tratado de Córdoba, por el cual se reconocía la independencia de México, con la condición de que éste formaría una monarquía parlamentaria, y su jefe de Estado sería Fernando VII. Mientras tanto, se convocaron a elecciones para conformar el primer congreso constituyente del México independiente.

El Congreso Constituyente quedó conformado con una inmensa mayoría de criollos, y tras llegar la noticia de que las Cortes de Cádiz repudiaban el Tratado de Córdoba, un sector de diputados pro Iturbide, desató una revuelta en la Ciudad de México; logrando que el Congreso designara a Agustín de Iturbide como emperador. De esa forma los dos únicos Estados de América que se independizaron de un imperio para convertirse en otro, fueron México y Brasil.

El Imperio duró poco más de ocho meses, y tras sucesivos levantamientos alrededor del país luego de la decisión del emperador de disolver el Congreso Constituyente; el 19 de marzo de 1823 es obligado a abdicar. Se conformó de esa manera un Supremo Poder Ejecutivo, liderado por tres juristas, quienes, a su vez, convocaron a un nuevo Congreso Constituyente.

En julio de ese año las provincias centroamericanas optaron por su independencia, en tanto que en el Congreso se vivía una división entre diputados que consideraban al régimen centralista como el idóneo y aquellos que apoyaban al federalismo. Al final de cuentas, fueron estos últimos quienes lograron la mayoría, y de esa forma, el 31 de enero de 1824, "el Congreso Constituyente aprobó el Acta Constitutiva de la Federación, instrumento jurídico para el gobierno y la organización política provisional, en tanto se concluía y aprobaba la Carta Magna".'"

"Las discusiones de los constituyentes, iniciadas el primero de abril, concluyeron el 4 de octubre del mismo año, día en que se dio a conocer a la nación mexicana la Constitución Federal de los Estados Unidos Mexicanos, redactada y aprobada por el Congreso Constituyente." ${ }^{18}$

${ }^{17}$ Calzada Padrón, Feliciano, op cit., p. 65.

${ }^{18}$ Ídem. 
Este texto constitucional se componía de I7| artículos, inspirados totalmente en la Constitución de los Estados Unidos de América. En ninguno de ellos, y en manera de cierto retroceso, se hacía mención de algún tipo de derecho fundamental.

La vida política mexicana se vería envuelta en el caos político, económico y social. Este gran período de crisis, que va desde la conclusión del primer gobierno republicano ( I 829) hasta el Plan de Ayutla (0 I de marzo de 1854), tuvo como rasgo fundamental la total anarquía y la inestabilidad política. Los golpes de Estado fueron comunes, y el cambio en la forma de gobierno era totalmente radical.

En este breve período caracterizado por la primera intervención francesa en México, conocida como la "Guerra de los Pasteles" y la invasión de los Estados Unidos de América -en la cual se perdería más de la mitad del antiguo territorio virreinal-; hubo tres documentos constitucionales, cada uno de los cuales despojaba al anterior de vigencia e instituía una nueva forma de gobierno.

Dentro de los documentos fundamentales que normaron la vida nacional, se encuentran:

a) Las Leyes Constitucionales - o también denominadas Siete Leyes — del 29 de diciembre de 1836. En ellas se creaba una república centralista, cuyo supremo poder se dividiría en cuatro: en el poder legislativo, ejecutivo, judicial y el Supremo Poder Conservador cuya función sería vigilar a los tres poderes tradicionales y el respeto a la Constitución.

En la primera ley, a partir de su artículo 2, se establecían de nueva cuenta derechos fundamentales en materia de libertad, y en el artículo 3 se hacía referencia a las obligaciones de los mexicanos.

b) Las Bases de Organización Política de la Nación -llamadas también Bases Orgánicas_-del 13 de junio de 1843, transformaban la división del poder en México: eliminaba al Supremo Poder Conservador, quien fungía como un auténtico poder garante de la constitución.

"El nuevo texto constitucional se componía de once títulos y 202 artículos, cuya vigencia sólo sería de tres años, pues la lucha nacional por cambiar la forma de gobierno y retornar al sistema federal aún no cesaba." ${ }^{19}$ A pesar de ello, las Bases Orgánicas regulaban derechos fundamentales, y lo hacían, vale la pena decirlo, de manera un tanto particular.

${ }^{19}$ Ibídem, p. 72. 
En el artículo 9, que hacía parte del título II de nombre "De los habitantes de la República", se enlistaban en catorce fracciones todos los derechos fundamentales que reconocía el Estado centralista. Era, además, de carácter exclusivo, pues el artículo décimo excluía a los extranjeros residentes en el país. De esa manera, se reconocían, según cada fracción: I. La proscripción de la esclavitud; II. Libertad de expresión y de imprenta; III. Regulación de escritos religiosos según la ley y la prohibición de escribir sobre la vida privada; IV. Garantía judicial en delitos de imprenta; V. Garantía de seguridad jurídica contra detenciones arbitrarias; VI. Garantía de seguridad jurídica contra actos privativos.; VII. Derecho a ser presentado ante autoridad judicial antes de los 30 días siguientes de haberse presentado la aprehensión; VIII. Proscripción de fueros especiales; IX. Derecho a la caución en procesos penales; $X$. Nulidad de la confesión obtenida mediante tortura o coacción; XI. Inviolabilidad del hogar; XII. Prohibición de pago de impuestos no contemplados por el Poder Legislativo; XIII. Derecho a la propiedad; y XIV. Libertad de tránsito.

Asimismo, en el artículo 19 se estipulaban derechos para los ciudadanos mexicanos, en especial el derecho a votary ser electo para cargos de representación popular.

c) El Acta Constitutiva y de Reformas del I 8 de mayo de I847. Este documento es producto de la profunda crisis que se vivía en México en esa época. Desde I 846, los Estados Unidos de América habían iniciado una invasión masiva con la intención de expandirse hacia el Océano Pacífico. Los políicos mexicanos se preocuparon más por hacerse del poder que por combatir al invasor. Dentro de esa necedad antipatriótica, los liberales se hicieron con el poder; acto seguido, convocaron a un Congreso Constituyente Extraordinario, mismo que promulgó el Acta Constitutivay de Reformas que cambiaba la forma de gobierno a una federación, retomaba la vigencia de la Constitución de 1824 y facultaba al ejecutivo federal expropiar y ocupar los bienes del clero, tan necesarios para combatir a los estadounidenses.

El artículo 5 de este documento señalaba que "Para asegurar los derechos del hombre que la Constitución reconoce, una ley fijará las garantías de libertad, seguridad, propiedad e igualdad de que gozan todos los habitantes de la República, y establecerá los medios de hacerlas efectivas."

Tras acabar la guerra con los Estados Unidos con la firma del Tratado de Guadalupe, el 2 de febrero de 1848, la inestabilidad política en México continuó. Los centralistas lograron ocupar de nueva cuenta el Poder y se impuso una dictadura militar, a manos de Antonio López de Santa Anna.

El descontento popular en aumento y una reorganización de los liberales, provocaron la Proclamación del Plan de Ayutla. "Los principales puntos del Plan consideraban: I o. desconocer a Santa Anna y a su régimen dictatorial; 2o. establecer un gobierno provisional, que sería sostenido con las fuerzas de las armas; 30 . convocar a un Congreso Constituyente tan pronto como triunfara el movimiento que iniciaban; 40. 
restablecer como forma de gobierno el sistema republicano representativo popular." ${ }^{20}$

Liderados por el general Juan Álvarez, los liberales se hicieron con el poder en 1855. "En el transcurso de los cuatro meses que duró en el poder, el general Álvarez convocó al Congreso Constituyente ( 6 de octubre de 1855)."." El Congreso Constituyente inició sus sesiones el 18 de febrero de 1856. "El resultado de sus trabajos fue la Nueva Carta Magna, que sería concluida el 5 de febrero de I 857."22

De esa manera, nació la Constitución Política de la República Mexicana, la cual en su título primero - del artículo I al 29-consagraba "los derechos del hombre". El artículo primero mencionaba que "El pueblo mexicano [reconocía] que los derechos del hombre [eran] la base y el objeto de las instituciones sociales. En consecuencia, [declaraba] que todas las leyes y las autoridades del país [debían] respetar y sostener las garantías que [otorgaba] la presente Constitución."

Enlistaba los derechos de:

I. Proscripción de la esclavitud (art. 2);

II. Libertad de enseñanza (art. 3);

III. Libertad de trabajo (art. 4y 5);

IV. Libertad de expresión (art. 6);

V. Libertad de imprenta (art. 7)

VI. Derecho de petición ante la autoridad (art. 8);

VII. Libertad de asociación (art. 9);

VIII. Derecho a la libre portación de armas (art. I0);

IX. Libertad de tránsito (art. I I);

X. Proscripción de los títulos nobiliarios (art. 12);

XI. Proscripción de tribunales especiales (art. 13);

XII. La irretroactividad de la ley (art. I4);

XIII. Proscripción de la extradición de reos políticos (art. I5);

XIV. Garantía de seguridad jurídica por actos de molestia (art. 16);

XV. Garantías en el proceso penal (art. 17, 18, 19, 20, 21, 22, 23 y 24);

XVI. La inviolabilidad del correo (art. 25);

XVII. La inviolabilidad del derecho de propiedad (art. 26 y 27);

XVIII.Proscripción de los monopolios (art. 28); y

XIX. La suspensión de garantías (art. 29).

\footnotetext{
${ }^{20}$ Ibídem, p. 82

${ }^{21}$ Ibídem, p. 83.

${ }^{22}$ Ídem.
} 
Esta regulación era de carácter universal, pues el artículo 33, destinado a los extranjeros, establecía que tenían derecho a las garantías otorgadas en el título I.

Asimismo, la nueva constitución introducía una figura para hacer efectivo el cumplimiento de los derechos del hombre, institución que había estado carente en otras constituciones: el juicio de amparo.

Antes que la Federación, fue una entidad la que tuvo en sus normas la previsión de lo que hoy ha venido a ser el juicio de amparo. "En el año de 1840 , el estado de Yucatán tomó determinadas medidas de carácter muy independiente —debido a su aislamiento del resto de la República, y al hecho de que ésta continuamente tenía problemas políticos y luchas por el poder-, y que hizo pensar en que deseaba dicho estado separarse de la Federación".

El principal impulsor de este proyecto fue el ilustre jurista don Manuel Crescencio Rejón. ${ }^{23}$

(...)

El artículo 7o. de la citada Constitución contenía las denominadas garantías individuales, las que — se decía — eran "derechos de todo habitante del Estado, sea nacional o extranjero", dando posteriormente un listado de doce derechos fundamentales. Asimismo, en su artículo 8o. se preveía que "los jueces de primera instancia ampararán en el goce de los derechos garantidos por el artículo anterior, a los que les pidan su protección contra cualquier funcionario que no correspondan al orden judicial, decidiendo breve y sumariamente las cuestiones que se susciten sobre los asuntos indicados [sic]".

En su artículo 9o. plasmaba la defensa de las violaciones a las garantías individuales por parte de los funcionarios del orden judicial, ordenando que: "De los atentados cometidos por los jueces contra los citados derechos, conocerán sus respectivos superiores con la misma preferencia de que se ha hablado en el artículo precedente, remediando desde luego el mal que se les reclame, y enjuiciando inmediatamente al conculcador de las mencionadas garantías".

Mas lo que verdaderamente constituyó un progreso en el derecho público mexicano fue la creación del medio controlador o conservador del régimen constitucional o amparo, como [Rejón] lo llamó, ejercido o desempeñado por el Poder Judicial, con la ventaja de que dicho control se hacía extensivo a todo acto (lato sensu) anti constitucional. Los lineamientos generales esenciales del juicio de amparo establecidos por las Constituciones de 1857 y 1917 se encuentran en la obra de

${ }^{23}$ Fernández Fernández, Vicente, "El juicio de amparo: historia y futuro de la protección constitucional en México", Revista IUS, vol. 5, n. 27, Instituto de Ciencias Jurídicas de Puebla, Departamento de Investigaciones, Puebla enero-junio, 201 I , p. 177. 
Rejón, quien lo hacía procedente contra cualquier violación a cualquier precepto constitucional, siempre y cuando representara un agravio personal. Daba Rejón competencia a la Suprema Corte para conocer de todo juicio de amparo contra actos del gobernador del Estado (Poder Ejecutivo) o leyes de la Legislatura (Poder Legislativo) que entrañaran una violación al código fundamental. A los jueces de primera instancia también Rejón los reputaba como órganos de control, pero sólo por actos de autoridades distintas del gobernador y de las legislaturas que violaran las garantías individuales, siendo los superiores jerárquicos de los propios jueces quienes conocían de los amparos interpuestos contra sus actos por análogas violaciones constitucionales. ${ }^{24}$

\section{La Constitución Política de los Estados Unidos Mexicanos}

La vigencia de la Constitución Política de la República Mexicana de 1857 fue difícil, debido, sobre todo, a la continua lucha que vivió el país entre los liberales y conservadores, la cual llevaría a una verdadera guerra civil conocida como la Guerra de Reforma.

La supresión de múltiples privilegios hacia el ejército y el clero, trajo consigo que éstos desconocieran al gobierno emanado de la Constitución y nombraran a un presidente interino. De esa manera, comenzó un conflicto que duraría tres años, y acabaría con la imposición de Maximiliano de Habsburgo por Napoleón III, con respaldo de los conservadores.

El Imperio instaurado duraría de 1862 a 1867 y acabaría con el fusilamiento del emperador a manos de los liberales. Benito Juárez, quien había sido la cabeza del ejecutivo interino, se proclamó como presidente constitucional para el período de 1868 a 1872, y al finalizar su mandato buscó la reelección. Uno de sus generales más fieles, Porfirio Díaz Mori, molesto por esa decisión, proclamó el Plan de la Noria desconociendo a Juárez; al final se llegó a un armisticio con el presidente, quedando sin consecuencias el levantamiento.

La muerte sorprendió a Juárez en 1872, y al fallecer, en elecciones extraordinarias, Sebastián Lerdo de Tejada venció a Porfirio Díaz. Aquél gobernó hasta 1876, y cuando quiso reelegirse, de nueva cuenta Díaz se levantó en armas con el Plan de Tuxtepec, logrando hacerse con el poder.

Porfirio Díaz encabezó el gobierno provisional mientras convocaba a elecciones federales, de las cuales él fue el vencedor. Gobernó de esa manera de 1876 a I880, sin poderse reelegir pues la Constitución de 1857 contemplaba esa prohibición; sin

${ }^{23}$ Fernández Fernández, Vicente, "El juicio de amparo: historia y futuro de la protección constitucional en México", Revista IUS, vol. 5, n. 27, Instituto de Ciencias Jurídicas de Puebla, Departamento de Investigaciones, Puebla enero-junio, 201 I , p. 177. 
embargo, escogió como sucesor a un compadre suyo, Manuel González, quien en su periodo presidencial reformó la constitución para permitir la reelección presidencial mediata.

Fue de esa manera que en 1884 Porfirio Díaz ocupó por segunda vez la presidencia de México, antes de acabar su mandato modificó de nueva cuenta la Carta Magna con tal de reelegirse "por una sola vez"; y así en I 888 fue reelecto. En su tercera presidencia, el general sencillamente permitió la reelección indefinida.

A este periodo de la historia nacional se le conoce con el nombre de "El Porfiriato" y trajo consecuencias controvertidas hasta el día de hoy. Por un lado, al lograr por primera vez la ansiada estabilidad desde la instauración de la república, trajo consigo confianza en la situación nacional, y con ella, la inversión extranjera apostó al proyecto del general.

El capital extranjero que más invirtió en México fue el de Estados Unidos, aunque también en menor medida hubo de Inglaterra, Francia y Alemania. A partir de 1894 se logró tener el primer superávit comercial, por lo que el remanente fue utilizado en infraestructura. Con ayuda de inversionistas estadunidenses, se logró unir al país a través del ferrocarril, lo cual también impulsó las exportaciones con el vecino del norte.

Se descubrieron, asimismo, grandes reservas petrolíferas en el Golfo de México, lo que llevó al país a proyectarse por primera vez al mercado mundial, ocupando un puesto de proveedor de materias primas.

Con tal de perdurar en el poder, el general permitió abusos de la más diversa índole. Otorgó miles de hectáreas en calidad de verdaderos feudos a aliados suyos; convirtió a México en un paraíso fiscal con tal de que grandes inversores trajeran capital. Un ejemplo de lo anterior, fue la dación de un poblado entero, Cananea, en Sonora, a una empresa estadounidense, la Cananea Consolidated Copper Company.

La empresa, como era natural, concedió cargos de importancia a trabajadores estadounidenses a costa de los mexicanos. A pesar de que estos últimos conformaban la mayoría de la empresa, los extranjeros percibían por funciones idénticas sueldos muy superiores. Además, con tal de que las ideas sindicalistas no infiltraran las mentes de los trabajadores mexicanos, las libertades de asociación y de prensa eran controladas por la compañía, a sabiendas y el consentimiento de las autoridades mexicanas.

En el campo la situación no era muy diferente, quizá hasta peor. Al dar grandes extensiones de tierras a latifundistas, en México se vivió una verdadera esclavitud. Los indígenas que protestaban por el arrebato de sus comunidades por parte del gobierno federal, eran fuertemente reprimidos y vendidos como esclavos a hacendarios en Yucatán.

Mediante créditos impagables que otorgaban las tiendas de ralla dentro de las haciendas, se creaban verdaderos monopolios de bienes básicos, y los peones debían trabajar durante generaciones hasta finiquitar su deuda, lo cual nunca acontecía.

En los inicios del siglo $X X$ las ideas anarco - sindicalistas fueron permeando en la sociedad obrera mexicana; propulsando huelgas alrededor del país. La primera en estallar ocurrió precisamente en Cananea (1906), siendo violentamente reprimida por rangers traídos directamente de Estados Unidos. Otro paro laboral que tuvo 
trascendencia, sucedió en una fábrica textil en Río Blanco, Veracruz, en 1907. Su origen fue la restricción en la libertad de recibir gente en casa de los obreros y en la prohibición de leer determinados textos. El saldo fue una verdadera matanza orquestada por el gobierno federal.

La situación social iba en detrimento a comparación del auge económico que el país vivía. En la política se generó especulación sobre la sucesión presidencial, pues el régimen del general Díaz no se había renovado, y al pasar del tiempo, parecía petrificarse más.

En 1908 el general concedió una entrevista a James Creelman para el Pearson's Magazine, en el cual Díaz afirmaba que México se encontraba listo para la democracia y que él incluso apoyaría a la futura oposición. Publicada la entrevista, en México se vivió un nuevo aire democrático y rápidamente surgieron partidos políticos que proponían un cambio en la silla presidencial.

Al final de cuentas el dictador volvió a reelegirse, deshaciéndose días previos a la elección de todos los opositores, entre ellos a Francisco I. Madero, candidato por el Partido Antirreleccionista. Preso él en la ciudad de San Luis Potosí, días después de la reelección del general, huyó a San Antonio, Texas, donde promulgó el Plan de San Luis por el cual convocaba a una revolución armada contra el dictador para el día 20 de noviembre de 1910 .

Lideró una serie de escaramuzas contra ciudades fronterizas mexicanas, que culminó con la firma de los Tratados de Ciudad Juárez, en virtud de los cuales Porfirio Díaz renunciaba a la presidencia y se creaba un gobierno interino cuyo único fin sería convocar a elecciones federales.

Madero obtuvo más del 90 por ciento de los votos, y se proclamó presidente de la República Mexicana. Su mayor error fue confiar en que el país sólo tenía un problema: la renovación presidencial. De hecho, decidió colocar en puestos claves a antiguos porfiristas, y pasados escasos dos años de mandato, el general Victoriano Huerta, con ayuda de otros porfiristas y del embajador de los Estados Unidos, encabezó un golpe de Estado, mandando asesinar tanto al presidente como al vicepresidente.

En este momento la revolución total estalló. Emiliano Zapata se alzó en armas al sur de la Ciudad de México, en el estado de Morelos; el gobernador de Coahuila, Venustiano Carranza, solicitó autorización y fondos al congreso local con tal de acudir a defender la Constitución. Él mismo se aseguró el apoyo de parte del ejército leal a Madero en Sonora, y junto con el teniente Álvaro Obregón liderando la División del Noroeste y Doroteo Arango, "Pancho Villa" comandando la División del Norte; Venustiano Carranza al mando del Ejército Constitucionalista, marchó hacia la capital del país.

El 15 de julio de 1914 Victoriano Huerta renunció a la presidencia, y al llegar a la capital Venustiano Carranza, tal como lo había prometido, convocó a una convención "revolucionaria". La Convención se instaló a petición de villistas y zapatistas en la ciudad de Aguascalientes, por considerarla neutral. Una vez instalada, la Convención se declaró soberana y desconoció a Carranza, quien a su vez, repudió al presidente electo por la 
Convención, Eulalio Gutiérrez; y marchó hacia Veracruz.

En ese momento el país quedó dividido en dos bandos: por un lado, villistas y zapatistas y por el otro, los carrancistas. Álvaro Obregón, máximo comandante de Venustiano Carranza, logró hacerse de victorias cruciales frente a Villa y Zapata; y tras recibir el reconocimiento oficial como gobernador de facto por parte de Estados Unidos, Venustiano Carranza convocó a un Congreso Constituyente.

El I 5 de septiembre de 1916, Carranza expidió un decreto por el que se llamaba a elecciones de un Congreso Constituyente. Se estableció la votación directa para los diputados, mismos que tendría que verificarse el día 22 de octubre de ese año. Los requisitos para votar y ser votado fueron los mismos que aquéllos establecidos en la constitución de 1857. Se ocuparon, a su vez, los distritos electorales de la elección pasada de 1912. Se citaba a una junta preparatoria el día 22 de noviembre y el inicio de sesiones estaba estipulado para el primero de diciembre del año en cuestión en la Ciudad de Querétaro.

Se presentó un verdadero apartidismo dentro del Constituyente, lo que provocó la radicalización de las opiniones de los diputados. No obstante, se crearon dos grupos extremos: izquierdas exaltadas y derechas moderadas.

Los más radicales se relacionaban con Obregón, en tanto que los más moderados con Carranza. Entre los primeros había muchos que pelearon en los campos de batalla y querían destruir rápidamente el pasado para entrar en el porvenir que habían soñado para México, entre ellos Francisco J. Múgica, Esteban Baca Calderón, Heriberto Jara, Cándido Aguilar, Juan de Dios Bojórquez, Rafael Martínez de Escobar, Luis Espinosa y Froylán Manjarrez. El ala moderada tuvo como núcleo fundamental a los ex diputados renovadores.

Carranza presentó un proyecto de reformas moderadas a la Constitución de |857, pero los diputados vieron más allá de un simple cambio, y propusieron disposiciones totalmente innovadoras para la época.

Empezando por el artículo primero: en la Constitución de I 857 se reconocían como derechos del hombre los que a continuación la propia Constitución enlistaba como tales. El nuevo texto adoptado por los diputados señalaba que las garantías individuales son los que otorga la Constitución. La diferencia en cuanto a los términos planteados es enorme. Cuando la Constitución "reconoce" -como lo mencionaba la de 1857-se tiene la idea de que los derechos existen incluso antes de que se escriban en papel, es decir, son inherentes al ser humano. Los diputados fueron radicales y señalaron que era la propia Constitución la que otorgaba y creaba las garantías individuales.

Ya desde la Declaración del Hombre y del Ciudadano francesa, se había establecido una clara diferencia entre los derechos y las garantías habidas para hacerlos efectivos. Parecida distinción había tomado el artículo 5 del Acta Constitutiva y de Reformas, y se consideraba que el concepto de "derechos del hombre" que señalaba la Constitución de 1857, los hacía menos efectivos; y por lo mismo, decidieron denominarlos "garantías individuales." 
Las discusiones más interesantes se centraron en los artículos 5, 27, I 23 y 130 :

El artículo 27 tomaba elementos de la Constitución de Cádiz, al reconocer que todas las tierras, sus recursos y el subsuelo pertenecían originalmente a la Nación, pero que ésta daba en usufructo, creando la propiedad privada, y por lo mismo, por causas de interés público podría expropiarse y recuperar en términos de la ley reglamentaria. Se estableció también la pequeña propiedad como aspiración de los campesinos del norte.

En la parte orgánica, Venustiano Carranza decidió cambiar el nombre de República Mexicana a "Estados Unidos Mexicanos". El Primer Jefe del Ejército Constitucionalista consideraba que la Constitución de 1857 había sido demasiado liberal, pues daba muchas prerrogativas al Poder Legislativo Federal, por lo que las principales reformas que necesitaba el país no podían concretarse con un Ejecutivo débil; Carranza, por tanto, modificó la figura del ejecutivo de la Federación, dando como resultado el sistema presidencialista que tenemos hoy en día.

El artículo 123 fue de especial análisis y discusión. A pesar de que la Constitución ya tenía el derecho al trabajo como una garantía individual en su artículo 5, los diputados fueron reacios a crear un apartado especial que contuviera una garantía social. Consideraron, por tanto, al trabajo como un deber y derecho nacionales. El ala moderada creía que la regulación tan excesiva que se proponía al artículo I 23 debería corresponder a una ley reglamentaria, no obstante, los radicales consideraban oportuno que la propia constitución estipulara las bases de toda relación laboral.

Otro artículo que fue objeto de radicalización fue el 130, que trataba de definir las relaciones que habría entre Iglesia y Estado. Los diputados en este aspecto rechazaron de plano la propuesta de Carranza, y llegaron al extremo de no reconocerle ningún tipo de personalidad a la Iglesia, erigiendo un Estado sumamente laico.

Hablando de derechos fundamentales, la nueva constitución tomaba como base la redacción y el orden de los artículos de la Constitución de 1857 para enumerar las nuevas garantías individuales; quedando éstas establecidas en el título primero de la constitución de los artículos primero al 28, terminando con el artículo 29 que habla sobre la suspensión de garantías.

Las sesiones del Congreso Constituyente terminaron el 31 de enero de 1917, y el día 5 de febrero en sesión solemne, Venustiano Carranza promulgó la Constitución Política de los Estados Unidos Mexicanos. En ese mismo instante, el gobierno de los Estados Unidos de América reconoció de iure a la facción constitucionalista.

\section{LOS DERECHOS ECONÓMICOS, SOCIALES Y CULTURALES EN EL SISTEMAJURÍDICOMEXICANO}

\section{Constitución Política de los Estados Unidos Mexicanos}

La Constitución Política de los Estados Unidos Mexicanos tuvo un origen esencialmente revolucionario. Fue producto de una guerra civil que tenía convulsionado al país desde hacía seis años, y sus redactores habían vivido en carne propia la 
explotación agrícola y obrera.

Por ese motivo, la constitución mexicana fue la primera norma fundamental de carácter social. En lo que hace a su parte dogmática ${ }^{25}$, la redacción de los artículos es idéntica: el Estado se obliga hacia el individuo a otorgarle prestaciones básicas.

La Oficina del Alto Comisionado de las Naciones Unidas para los Derechos Humanos define a los derechos económicos, sociales y culturales como "los derechos humanos relacionados con el lugar de trabajo, la seguridad social, la vida en familia, la participación en la vida cultural y el acceso a la vivienda, la alimentación, el agua, la atención de la salud y la educación. ${ }^{26}$

En este aspecto, la Constitución de 1917 reconoce todos y cada uno de los derechos humanos definidos por Naciones Unidas, yendo incluso más lejos que el organismo internacional.

Tratándose del derecho al trabajo y a la seguridad social, México cuenta con una doble protección en el Derecho nacional. El artículo 5 de la constitución actual reconoce la libertad del trabajo como un derecho individual; mientras que el artículo 123 estipula las condiciones básicas que todo trabajador deberá contar en su relación laboral, entre ellas la duración máxima de la jornada, la regulación del trabajo hecho por menores de edad, mujeres embarazadas; las reglas especiales sobre el salario, etc. Asimismo, la fracción XXIX del artículo en comento, prevé un derecho para el trabajador un poco peculiar: el derecho de contar con una ley de seguridad social que comprenda "seguros de invalidez, de vejez, de vida, de cesación involuntaria del trabajo, de enfermedades y accidentes, de servicios de guardería y cualquier otro encaminado a la protección y bienestar de los trabajadores, campesinos, no asalariados y otros sectores sociales y sus familiares." ${ }^{\prime 27}$

En cuanto a los demás derechos que la Organización de las Naciones Unidas reconoce como derechos económicos, sociales y culturales, la Constitución mexicana desde 1917 ha regulado a todos ellos en un solo artículo constitucional: el cuarto.

El actual texto de este artículo es el siguiente:

Artículo 4o. El varón y la mujer son iguales ante la ley. Esta protegerála organización y el desarrollo de la familia.

Toda persona tiene derecho a decidir de manera libre, responsable e informada sobre el número y el espaciamiento de sus hijos.

Toda persona tiene derecho a la alimentación nutritiva, suficiente y de calidad. El Estado lo garantizará.

${ }^{25}$ Que comprende desde el artículo I al 29.

${ }^{26}$ Preguntas frecuentes sobre los derechos económicos, sociales y culturales, Boletín Informativo n. 33, Organización de las Naciones Unidas, Ginebra, Suiza, p. 3.

${ }^{27}$ Cfr. Artículo I 23, fracción XXIX de la Constitución Política de los Estados Unidos Mexicanos. 
Párrafo adicionado DOF 13-10-2011

Toda persona tiene derecho a la protección de la salud. La Ley definirá las bases y modalidades para el acceso a los servicios de salud y establecerá la concurrencia de la Federación y las entidades federativas en materia de salubridad general, conforme a lo que dispone la fracción XVI del artículo 73 de esta Constitución.

Párrafo adicionado DOF 03-02-1983

Toda persona tiene derecho a un medio ambiente sano para su desarrollo y bienestar. El Estado garantizará el respeto a este derecho. El daño y deterioro ambiental generará responsabilidad para quien lo provoque en términos de lo dispuesto por la ley.

Párrafo adicionado DOF 28-06-1999. Reformado DOF 08-02-2012

Toda persona tiene derecho al acceso, disposición y saneamiento de agua para consumo personal y doméstico en forma suficiente, salubre, aceptable y asequible.

El Estado garantizará este derecho y la ley definirá las bases, apoyos y modalidades para el acceso y uso equitativo y sustentable de los recursos hidricos, estableciendo la participación de la Federación, las entidades federativas y los municipios, así como la participación de la ciudadanía para la consecución de dichos fines.

Párrafo adicionado DOF 08-02-2012

Toda familia tiene derecho a disfrutar de vivienda digna y decorosa. La Ley establecerá los instrumentos y apoyos necesarios a fin de alcanzar tal objetivo.

Como se aprecia los derechos económicos, sociales y culturales han presentado una tendencia a aumentar su contenido, no sólo en México sino a nivel mundial, tomando en consideración las nuevas necesidades que pueden llegar a presentarse.

Al Derecho corresponderá, en su carácter de motor de cambio social, poner a debate la necesidad de aumentar o disminuir el contenido de este derecho fundamental.

En el sistema jurídico mexicano la protección de los derechos fundamentales se lleva a cabo a través de vías jurisdiccionales y no jurisdiccionales. Esto es, ante la violación de cualquier derecho fundamental, el ciudadano tiene la opción de acudir ante la justicia federal, promoviendo el juicio de amparo; o bien, acudir ante un órgano constitucionalmente autónomo: la Comisión Nacional de los Derechos Humanos.

A continuación, nos permitimos hacer una breve referencia a ambas protecciones de los derechos fundamentales en México.

\section{El Juicio de Amparo}

El análisis de este medio de convencionalidad debe partir necesariamente del estudio del artículo I 03 constitucional:

El citado artículo refiere:

Artículo 103. Los Tribunales de la Federación resolverán toda controversia que se suscite:

I. Por normas generales, actos u omisiones de la autoridad que violen los derechos 
humanos reconocidos y las garantías otorgadas para su protección por esta Constitución, así como por los tratados internacionales de los que el Estado Mexicano sea parte;

II. Por normas generales o actos de la autoridad federal que vulneren o restrinjan la soberanía de los Estados o a la autonomía de la Ciudad de México, y

III. Por normas generales o actos de las autoridades de las entidades federativas que invadan la esfera de competencia de la autoridad federal.

De forma complementaria, el artículo primero de la Ley de Amparo señala:

Artículo Io. El juicio de amparo tiene por objeto resolver toda controversia que se suscite:

I. Por normas generales, actos u omisiones de autoridad que violen los derechos humanos reconocidos y las garantías otorgadas para su protección por la Constitución Política de los Estados Unidos Mexicanos, asi como por los tratados internacionales de los que el Estado Mexicano sea parte;

II. Por normas generales, actos u omisiones de la autoridad federal que vulneren o restrinjan la soberanía de los Estados o la esfera de competencias del Distrito Federal, siempre y cuando se violen los derechos humanos reconocidos y las garantias otorgadas para su protección por la Constitución Politica de los Estados Unidos Mexicanos; $y$

III. Por normas generales, actos u omisiones de las autoridades de los Estados o del Distrito Federal, que invadan la esfera de competencia de la autoridad federal, siempre y cuando se violen los derechos humanos reconocidos y las garantías otorgadas por la Constitución Política de los Estados Unidos Mexicanos.

El amparo protege a las personas frente a normas generales, actos $\mathrm{u}$ omisiones por parte de los poderes públicos o de particulares en los casos señalados en la presente Ley.

Del análisis de ambos preceptos, la Suprema Corte de Justicia de la Nación ha señalado que el juicio de amparo "es un medio de control constitucional cuyo objeto es reparar las violaciones de garantías que un determinado acto de autoridad genera sobre la esfera jurídica del gobernado que lo promueva, con el fin de restituirlo en el pleno goce de sus derechos fundamentales que le hayan sido violados, el legislador ordinario ha establecido como principio que rige su procedencia la circunstancia de que el fallo

\footnotetext{
${ }^{28}$ Amparo directo en revisión 3044/98. Eduardo Cuauhtémoc Siller Leyva y otros. 12 de mayo de 2000. Cinco votos. Ponente: Ministro Guillermo I. Ortiz Mayagoitia. Derivado de este asunto véase Semanario Judicial de la Federación y su Gaceta, Novena Época, t. XXIV, diciembre de 2006, p. 189, tesis 2a./J. I8I/2006; IUS: 173858
} 
protector que en su caso llegare a emitirse pueda concretarse y trascender a la esfera jurídica del gobernado que lo haya promovido (...),28

En ese aspecto, el amparo constituye un verdadero juicio que realiza el Poder Judicial de la Federación para determinar, en un primer aspecto, si una autoridad ha violentado un derecho fundamental al promovente. Por ser estrictamente un proceso regulado por leyes federales que busca proteger los derechos fundamentales, al juicio de amparo se le conoce en la doctrina como juicio constitucional o juicio de garantías.

\section{La Comisión Nacional de los Derechos Humanos y las Comisiones Locales}

El 13 de febrero de 1989, dentro de la Secretaría de Gobernación, se creó la Dirección General de Derechos Humanos. Un año más tarde, el 6 de junio de 1990, nació, por decreto presidencial, una institución denominada Comisión Nacional de Derechos Humanos, constituyéndose como un organismo desconcentrado de dicha Secretaría.

Posteriormente, mediante una reforma publicada en el Diario Oficial de la Federación el 28 de enero de 1992, se adicionó el apartado B, al artículo 102 de la Constitución Política de los Estados Unidos Mexicanos, dando surgimiento al sistema nacional no jurisdiccional de protección de los derechos humanos. ${ }^{29}$

La protección no jurisdiccional de los derechos fundamentales descansa tanto en la Comisión Nacional de los Derechos Humanos como en las comisiones de Derechos Humanos locales; de estas últimas hay una por cada uno de los treinta y dos estados federativos.

La competencia entre las distintas comisiones depende del nivel al que pertenezca la autoridad que violenta el derecho fundamental. Al existir competencia recurrente, la Comisión Nacional de los Derechos Humanos conoce del caso.

Por disposición del apartado B del artículo 102 constitucional, las comisiones formularán recomendaciones públicas no vinculatorias respecto a las quejas que sean presentados ante ellas. Ello ha disminuido la efectividad de la protección no jurisdiccional, pues las autoridades no quedan obligadas a cumplir las resoluciones emanadas de la Comisión Nacional y de las comisiones locales. No obstante, el propio artículo en comento señala que es facultad del Senado de la República, citar a las

${ }^{29}$ Castañeda, Mireya, La protección no jurisdiccional de los derechos humanos en México, Colección de textos sobre derechos humanos, Comisión Nacional de los Derechos Humanos, México 2015, p. 28 y 29 
autoridades que no cumplan las recomendaciones para que fundamenten y motiven su negativa.

Asimismo, la Constitución ha otorgado medios de control de la constitucionalidad a las comisiones, en específico, la acción de inconstitucionalidad; la cual es la garantía constitucional que insta el control abstracto de una norma general ante la Suprema Corte de Justicia de la Nación, a efecto de que ésta pueda determinar si existe una contradicción entre aquélla y la Constitución Política de los Estados Unidos Mexicano y los tratados internacionales de los que México es parte.

\section{Reforma Constitucional en materia de Derechos Humanos}

Los días 6 y 10 de junio del 201 I marcaron una inflexión en el Derecho Constitucional Mexicano, y sobre todo, en lo que respecta a los derechos humanos.

En estas fechas, fueron publicados dos importantes decretos por los que se modificaban sustancialmente el artículo primero constitucional y prácticamente se promulgaba una nueva Ley de Amparo, hecha con base en las múltiples jurisprudencias que el Poder Judicial de la Federación había emitido para adecuar la justicia mexicana.

En materia constitucional, se substituía la expresión "garantías individuales" por la de "derechos humanos". De esa forma, el capítulo primero del título primero de la constitución federal se denominó "De los Derechos Humanos y sus Garantías", iniciando la carta fundamental de la siguiente forma:

"Artículo Io. En los Estados Unidos Mexicanos todas las personas gozarán de los derechos humanos reconocidos en esta Constitución y en los tratados internacionales de los que el Estado Mexicano sea parte, así como de las garantías para su protección, cuyo ejercicio no podrá restringirse ni suspenderse, salvo en los casos y bajo las condiciones que esta Constitución establece.

Las normas relativas a los derechos humanos se interpretarán de conformidad con esta Constitución y con los tratados internacionales de la materia favoreciendo en todo tiempo a las personas la protección más amplia.

Todas las autoridades, en el ámbito de sus competencias, tienen la obligación de promover, respetar, proteger y garantizar los derechos humanos de conformidad con los principios de universalidad, interdependencia, indivisibilidad y progresividad. En consecuencia, el Estado deberá prevenir, investigar, sancionar y reparar las violaciones a los derechos humanos, en los términos que establezca la ley."

Esta adecuación del artículo constitucional fue objeto de múltiples comentarios. Ciertamente la reforma constitucional correspondió a las múltiples sentencias que la Corte Interamericana en Derechos Humanos dictó contra México.

El Poder Legislativo Federal, con bombo y platillo, celebró y presumió la adecuación como un suceso de enorme importancia, pues argumentaban que gracias a su labor la Constitución Federal reconocía los derechos humanos.

Lo cierto es que, desde el texto original de la constitución de 1917, los tratados 
internacionales hacían parte de las leyes de la unión. El artículo I33 constitucional estipula, a la letra:

Artículo 133. Esta Constitución, las leyes del Congreso de la Unión que emanen de ella y todos los tratados que estén de acuerdo con la misma, celebrados y que se celebren por el Presidente de la República, con aprobación del Senado, serán la Ley Suprema de toda la Unión. Los jueces de cada entidad federativa se arreglarán a dicha Constitución, leyes y tratados, a pesar de las disposiciones en contrario que pueda haber en las Constituciones o leyes de las entidades federativas.

De una interpretación literal, se advierte que las leyes federales que emanen de la Constitución y los tratados internacionales celebrados por el Presidente y ratificados por el Senado, constituyen la ley de la Federación. Por lo tanto, la Constitución adopta a todo pacto internacional que se encuentre celebrado acorde al procedimiento que ella mandata, sin importar el contenido que tenga. Por esa razón, los tratados internacionales en materia de derechos humanos hacían ya parte del sistema jurídico mexicano, y las constituciones estatales y sus autoridades, en todos los niveles, contaban con la obligación de hacerlas respetar en virtud del principio de supremacía constitucional.

El espíritu de la reforma, mostrada en su exposición de motivos, fue el equiparar a nivel constitucional los derechos humanos, sin que existieran interpretaciones contradictorias por el propio Poder Judicial.

Hay, no obstante, un efecto secundario que los legisladores no vislumbraron al introducir la nueva redacción: su interpretación.

El artículo 14 constitucional prevé, en su cuarto párrafo, cómo ha de realizarse la labor hermenéutica de la ley, al señalar que "En los juicios del orden civil, la sentencia definitiva deberá ser conforme a la letra o a la interpretación jurídica de la ley, y a falta de ésta se fundará en los principios generales del derecho.".

Analizando este precepto, la aplicación de la ley por parte de todos los tribunales en los juicios de orden civil -entendidos éstos como aquellos que son distintos al orden penal o criminal — se basará en primer lugar conforme a una interpretación literal. En caso de que ésta sea obscura, o dudosa, su interpretación deberá ser sistemática, es decir, encontrando el sentido de la disposición en su relación con el ordenamiento jurídico. Y sólo cuando haya imposibilidad de interpretar con base a la letra y en su relación con el sistema, se deberá acudir a los principios generales del Derecho.

A primera vista no hay conflicto entre las redacciones de los artículos I 4 y primero, pues debería entenderse que este último constituye una excepción normativa a la interpretación "del orden civil", y de esa manera, habría tres tipos de exégesis según el orden: una para Derecho penal o criminal; otra interpretación en materia de derechos humanos con base en principios; y los demás órdenes "civiles" (constitucional, laboral, civil, mercantil, etc.). 
Teóricamente no hay controversia, pero en la práctica se ha presentado una verdadera confusión de interpretaciones. Se han dado casos en que jueces aplican una revisión de la convencionalidad indebida, y deciden resolver casos de carácter civil o mercantil basados únicamente en los derechos humanos.

En concreto, jueces de primera instancia tienen asuntos en apelación porque en sus resoluciones consideraron que un título de crédito violentaba el derecho humano de proscripción a la usura; fallando a favor del deudor y no del acreedor. Para el juez es clara la transgresión del derecho humano reconocido en tratados internacionales, sin embargo, en la aplicación de la hermenéutica por él entendida, viola el derecho humano al debido proceso, mismo que se encuentra contenido en el artículo |4, pues interpreta por principios y no siguiendo la literalidad.

Este tipo de problemas son cada día más comunes en el foro, y traerán como consecuencia, un incremento en la carga de trabajo de los juzgados de segunda instancia en México, por cuestiones que antes de la citada reforma parecerían hasta burdas.

Lo anterior sólo se puede explicar por un factor: el atrevimiento. Una paradoja explica a la perfección este fenómeno: imagínese una jaula en la cual habita un canario. Si se abre la puerta, el canario puede reaccionar de tres maneras distintas: puede aprovechar y salir volando hacia el mundo exterior; o bien, quizá decida permanecer en la jaula por miedo a aquello que le rodea. Una tercera actitud posible, sería que fuera poco a poco saliendo de su prisión.

El canario referido son las actitudes de los jueces mexicanos: hubo quienes se abalanzaron hacia una interpretación basada en los derechos fundamentales y nada más; mismos que se han encontrado en el aprieto de tener que justificar decisiones a la luz injustas, como es el caso de quienes han resuelto a favor del deudor en títulos de crédito. Hay jueces que deciden no meterse en aprietos y tratan de resolver la controversia con Derecho nacional, sin meterse al análisis de normas internacionales, a pesar de que la Constitución les obliga.

Y el tercer perfil de juez es, quizá el más correcto: una posición media entre el miedo al control de la convencionalidad y ante el temerario que pretende encontrar la panacea en los derechos humanos.

Lo cierto es que, a partir de querer encontrar el mejor modelo de interpretación por principios, el Derecho mexicano revivió una disciplina filosófica: la Teoría de la Argumentación Jurídica.

Se vive en la academia una vorágine que incorpora a los planes de estudios materias como Argumentación Jurídica, Lógica y Hermenéutica. Los textos de Robert Alexy, Jürgen Habermas, Manuel Atienza, entre otros, son cada día más comunes en el primer ciclo universitario en las carreras de Derecho. El sistema jurídico mexicano necesita técnicas para ponderar principios y evitar resoluciones injustas a la luz de la Constitución mexicanay su convencionalidad. 


\section{El Sistema Interamericano de Derechos Humanos}

Corresponde a los Estados Americanos la conformación del organismo regional más antiguo del mundo. Las ideas que había plasmado Simón Bolívar en su Carta de Jamaica, serían llevadas a la práctica el 7 de diciembre de 1824, fecha en que "el Libertador" convocó a todas las naciones independientes de América a un primer congreso, en el cual se debatiría la confederación de todo el continente. Bolívar envió comunicaciones a todos los países latinoamericanos recién independizados y a los propios Estados Unidos, quienes enviaron dos representantes.

Asistieron, asimismo, plenipotenciarios de México, de la naciente Confederación de Centroamérica, de la Gran Colombia, de Bolivia y de Perú. Argentina se encontraba en conflicto con Brasil por la banda oriental del Uruguay, por lo que no tuvieron representación en el congreso.

Los representantes de Bolivia, por problemas de designación, no alcanzaron a llegar a tiempo; los plenipotenciarios estadounidenses tampoco pudieron arribar por cuestiones climáticas. Ni Chile ni Paraguay enviaron representación por motivos internos; y Haití ni siquiera fue convocado. De manera externa, la Gran Bretaña y los Países Bajos enviaron representantes, para tratar temas comunes con la América Latinoamericana.

Los problemas habidos entre los mimos Estados americanos ocasionaron que no se llegaran a acuerdos considerables. Dentro de la minuta a temas a tratar, se encontraban la eliminación de aranceles, con el objetivo de crear la primera zona de libre comercio, sin embargo, al ser éstos una de las principales fuentes de ingreso de los Estados independientes, y por la situación tan precaria de las balanzas de pago en todo el continente; se decidió desechar la propuesta.

Se obviaron temas generadores de conflictos, como fue el reconocimiento fronterizo entre los Estados. México y Centroamérica encabezaron las discusiones por Chiapas; le siguió la Gran Colombia contra la misma confederación. Se negó la pretensión bolivariana de ayudar a las colonias insulares (Cuba y Puerto Rico) a lograr su independencia, principalmente por injerencia del representante británico, quien no deseaba entablar una guerra con España.

Al final, y con bastantes dificultades, se logró suscribir el "Tratado magnífico titulado de la Unión, de la Liga, y de la Confederación perpetua”, cuyo artículo segundo establecía que el objeto del pacto perpetuo era "sostener en común, defensiva y ofensivamente si fuera necesario, la soberanía e independencia de todas y cada una de las potencias confederadas de América contra toda dominación extranjera y asegurarse,

\footnotetext{
${ }^{30}$ Tratado de Unión, Liga y Confederación Perpetua, en http://www.granma.cu/granmad/ secciones/alba/ant/2antec-0 I .html, consultado el día I de agosto del 2017.
} 
desde ahora, para siempre, los goces de una paz inalterable, y promover, al efecto, la mejor armonía y buena inteligencia, así entre los pueblos, ciudadanos y súbditos, respectivamente, con las demás potencias con quienes deben mantener o entrar en relaciones amistosas."

Sin embargo, "no entró en vigor ya que fue ratificado sólo [por] la Gran Colombia (Colombia, Ecuador, Panamá y Venezuela de hoy)." "

Se decidió posteriormente trasladar el Congreso a Tacubaya, localidad que en ese entonces se encontraba a las afueras de la Ciudad de México; pero al momento es que se supo que Perú no había ratificado el Tratado, los gobiernos latinoamericanos comenzaron a declinar el congreso bolivariano.

Debido a las dificultades habidas en toda la América Latina durante el siglo XIX, la integración jurídica latinoamericana quedó de lado, aunque hubo intentos de congresos, que resultaron fallidos. Fueron los Estados Unidos quienes tomaron la batuta de la integración americana, y en el año de 1889 convocaron a la Primera Conferencia Internacional Americana, a celebrarse en la ciudad de Washington D.C., del 2 de octubre de 1889 al 19 de abril de 1890. Los temas a tratarse dentro de la conferencia girarían entorno a temas comerciales; y se reunía a los Estados participantes con el objeto de discutir y recomendar a los respectivos Gobiernos la adopción de un plan de arbitraje para el arreglo de los desacuerdos y cuestiones que pudieran en lo futuro suscitarse entre ellos; de tratar de asuntos relacionados con el incremento del tráfico comercial y de los medios de comunicación directa entre dichos países; de fomentar aquellas relaciones comerciales recíprocas que fueran provechosas para todos y asegurar mercados más amplios para los productos de cada uno de los referidos países. ${ }^{31}$

Dieciocho Estados americanos participaron de esta Conferencia, en la que se acordó establecer una Unión Internacional de Repúblicas Americanas, con sede en Washington, D.C., "por medio de la cual se pueda obtener la pronta y exacta publicación, a costa y en provecho común, de datos comerciales importantes". ${ }^{32}$

De esa forma. se empezó a forjar una red de disposiciones y de instituciones que se conocería como "sistema interamericano". Por su fecha de creación, se considera el más antiguo del planeta.

Se realizaron un total de ocho Conferencias Internacionales Americanas, y en la novena, realizada en 1948 en Bogotá, Colombia, se llegó a la unanimidad de crear la Organización de Estados Americanos (OEA). Su objetivo, indicado en el artículo primero de la Carta de la Organización de los Estados Americanos, es lograr en sus Estados Miembros "un orden de paz y de justicia, fomentar su solidaridad, robustecer su colaboración y defender su soberanía, su integridad territorial y su independencia."

${ }^{31}$ Visto en la página electrónica de la Organización de Estados Americanos, en la página http://www.oas.org/es/acerca/nuestra_historia.asp, consultado el día I de agosto del 2017. ${ }^{32}$ Ídem. 
Al día de hoy, Antigua y Barbuda, Argentina, Bahamas, Barbados, Belice, Bolivia, Brasil, Canadá, Chile, Colombia, Costa Rica, Cuba, Dominica, Ecuador, El Salvador, los Estados Unidos de América, Granada, Guatemala, Guyana, Haití, Honduras, Jamaica, México, Nicaragua, Panamá, Paraguay, Perú, República Dominicana, Saint Kitts y Nevis, San Vicente y las Granadinas, Santa Lucía, Surinam, Trinidad y Tobago, Uruguay y Venezuela; conforman los treinta y cinco estados miembros.

Un avance gigantesco que se dio en la misma IX Conferencia Internacional Americana, fue la adopción de la Declaración Americana de los Derechos y Deberes del Hombre. A partir de ella, los "Estados americanos han adoptado una serie de instrumentos internacionales que se han convertido en la base normativa de un sistema regional de promoción y protección de los derechos humanos, al reconocer estos derechos, establecer obligaciones tendientes a su promoción y protección, y crear órganos destinados a velar por su observancia." ${ }^{33}$

Con la modificación a la Carta a través del Protocolo de Washington de 1992, se dispuso que uno de los propósitos fundamentales de la OEA es el de "promover, mediante la acción cooperativa, el desarrollo económico, social y cultural de los Estados Miembros y ayudar a erradicar la pobreza extrema del Hemisferio." ${ }^{\text {"4 }}$

El sistema interamericano de derechos humanos no sólo se integra por la Carta sino por los siguientes instrumentos: ${ }^{35}$

I) La Convención Americana sobre Derechos Humanos (llamado Pacto de San José).

2) La Convención Interamericana para Prevenir y Sancionar la Tortura.

3) El Protocolo Adicional a la Convención Americana sobre Derechos Humanos en materia de Derechos Económicos, Sociales y Culturales (Protocolo de San Salvador) 4) El Protocolo a la Convención Americana sobre Derechos Humanos relativo a la Abolición de la Pena de Muerte.

5) La Convención Interamericana para Prevenir, Sancionar y Erradicar la Violencia contra a Mujer (denominada también como Convención de Belém do Pará)

6) La Convención Interamericana sobre Desaparición Forzada de Personas.

7) La Convención Interamericana para la Eliminación de Todas las Formas de

${ }^{33}$ Documentos básicos de derechos humanos en el sistema interamericano. Introducción, p. 2 , consultado en http://www.oas.org/es/cidh/mandato/documentos_basicos.asp, el día I de agosto del 2017.

${ }^{34}$ Ibídem, p. 3.

${ }^{35}$ Cfr. Documentos básicos de derechos humanos en el sistema interamericano. Introducción, p. I -8.

${ }^{36}$ Aún no entra en vigor.

${ }^{37}$ Ídem. 
Discriminación contra las Personas con Discapacidad.

8) La Convención Interamericana contra el Racismo, la Discriminación Racial y Formas Conexas de Intolerancia. ${ }^{36}$

9) La Convención Interamericana contra toda Forma de Discriminación e Intolerancia. ${ }^{37}$

10) La Carta Democrática Interamericana.

I I) La Declaración de Principios sobre Libertad de Expresión.

12) Principios y Buenas Prácticas sobre la Protección de las Personas Privadas de la Libertad en las Américas.

\section{Protocolo de San Salvador}

El 17 de noviembre de 1988, en la ciudad de San Salvador, El Salvador, la Asamblea General de la Organización de Estados Americanos (OEA), dentro de su décimo octavo periodo ordinario de sesiones; aprobó el Protocolo Adicional a la Convención Americana sobre Derechos Humanos en Materia de Derechos Económicos, Sociales y Culturales, conocido de igual manera como el Protocolo de San Salvador.

Este instrumento fue suscrito por los Estados de Argentina, Bolivia, Costa Rica, Ecuador, El Salvador, Guatemala, Haití, México, Nicaragua, Panamá, Perú, República Dominicana y Uruguay. Aunque tiempo después, se adhirió Brasil (8 de agosto de 1996); Colombia (22 de octubre de 1997); Honduras (I 4 de septiembre del 20 I I); Paraguay (26 de agosto de 1996); Suriname (28 de febrero de 1990); y Venezuela (27 de enero de 1989).

Chile, Haití, República Dominicana y Venezuela, a pesar de haber firmado el Protocolo, no lo han ratificado.

Canadá y los Estados Unidos de América ni siquiera reconocen este instrumento, en parte, por las implicaciones que su adopción suscitaría en la política migratoria y económica, al reconocer derechos más amplios que los estipulados en su sistema jurídico.

El Protocolo contiene un total de 22 artículos, destinando del artículo 6 al 18 a la ampliación del catálogo de derechos económicos, sociales y culturales. El artículo segundo compromete a los Estados signatarios a "adoptar, con arreglo a sus procedimientos constitucionales y a las disposiciones de este Protocolo las medidas legislativas o de otro carácter que fueren necesarias para hacer efectivos tales derechos."

Este instrumento amplía el catálogo indicado por las Naciones Unidas de los derechos económicos, sociales y culturales básicos, ${ }^{38}$ pues añade, a éstos el derecho a un medio ambiente sano (artículo I I); el derecho a la niñez (artículo I6); la protección a

\footnotetext{
${ }^{38}$ Cfr. Supra Apartado III. I .
} 
los ancianos (artículo 17); y la protección de los minusválidos (artículo | 8).

El artículo 19 regula los medios de protección de estos derechos humanos mediante la presentación de informes por parte de los Estados miembros, en los cuales se señalen las medidas progresivas que han sido adoptadas en las legislaciones nacionales.

No obstante, el párrafo 6 y 7 del Protocolo señala:

6. En el caso de que los derechos establecidos en el párrafo a) del artículo 8 [derecho de libre sindicalización] y en el artículo 13 [derecho a la educación] fuesen violados por una acción imputable directamente a un Estado parte del presente Protocolo, tal situación podría dar lugar, mediante la participación de la Comisión Interamericana de Derechos Humanos, y cuando proceda de la Corte Interamericana de Derechos Humanos, a la aplicación del sistema de peticiones individuales regulado por los artículos 44 a 51 y 61 a 69 de la Convención Americana sobre Derechos Humanos. 7. Sin perjuicio de lo dispuesto en el párrafo anterior, la Comisión Interamericana de Derechos Humanos podrá formular las observaciones y recomendaciones que considere pertinentes sobre la situación de los derechos económicos, sociales y culturales establecidos en el presente Protocolo en todos o en algunos de los Estados partes, las que podrá incluir en el Informe Anual a la Asamblea General o en un Informe Especial, según lo considere más apropiado.

Derivado de la lectura del sexto párrafo de este artículo, la violación al derecho de los trabajadores a la libre sindicalización para defender sus intereses comunes, así como el derecho de toda persona a recibir educación, podrán ser denunciados ante la Comisión Interamericana de Derechos Humanos, y si ésta lo considerare, ser presentados ante la Corte Interamericana de Derechos Humanos.

\section{I La Comisión y la Corte Interamericana de Derechos Humanos}

Como se hizo referencia anteriormente ${ }^{39}$ la Convención Americana sobre Derechos Humanos - llamada también como Protocolo de San José-hace parte del Sistema Interamericano, y constituye, por su contenido, el instrumento internacional más importante sobre la materia en el continente.

Se divide en tres partes: la primera trata sobre los derechos fundamentales sustantivos, especificando cada uno de ellos; la segunda regula derechos adjetivos, es decir, cómo hacerlos efectivos; y la última refiere a procedimientos generales en cuanto a modificación, reserva y denuncia del Protocolo.

${ }^{39}$ Cfr. Supra Apartado III. 3. 
La segunda parte es la que toma relevancia en cuanto a garante de los derechos fundamentales contenidos en el Protocolo de San Salvador. El artículo 33 señala las autoridades competentes para conocer del incumplimiento de los compromisos contraídos por los Estados Partes, a saber:

a) La Comisión Interamericana de Derechos Humanos, llamada en adelante como

"Comisión"; y

b) La Corte Interamericana de Derechos Humanos, llamada en adelante la Corte.

La Comisión se compone de siete miembros, electos cada cuatro años, ${ }^{40}$ que se reputan por sus Estados nacionales como "personas de alta autoridad moral y reconocida versación en materia de derechos humanos." "La Comisión en todo momento representa a la OEA, y precisamente en ella recae la competencia para conocer de las denuncias o quejas de violaciones cometidas por los Estados miembros en perjuicio de cualquier persona, grupo de personas, o entidad no gubernamental de una o más Estados miembros de la Organización.

Los requisitos de procedibilidad son enumerados en el artículo 46 de la Convención, el cual indica que "para que una petición o comunicación presentada conforme a los artículos 44 ó 45 sea admitida por la Comisión, se requerirá:

a) que se hayan interpuesto y agotado los recursos de jurisdicción interna, conforme a los principios del Derecho Internacional generalmente reconocidos;

b) que sea presentada dentro del plazo de seis meses, a partir de la fecha en que el presunto lesionado en sus derechos haya sido notificado de la decisión definitiva;

c) que en el caso del artículo 44 la petición contenga el nombre, la nacionalidad, la profesión, el domicilio y la firma de la persona o personas o del representante legal de la entidad que somete la petición." (sic)

Los dos primeros requisitos no serán necesarios cuando no exista en la legislación interna el proceso para la protección del derecho que se estima violado; no se le haya permitido el acceso a la justicia interna injustificadamente al lesionado; o ésta se esté retardando sin justificación alguna. ${ }^{44}$

El procedimiento para la presentación de denuncias ante la Comisión se establece del artículo 48 al 5 I del Protocolo de San José.

\footnotetext{
${ }^{40}$ Artículo 37 del Protocolo de San José.

${ }^{41}$ Artículo 34 del Protocolo de San José.

${ }^{42}$ Artículo 35 del Protocolo de San José.

${ }^{43}$ Cfr. Artículo 44 del Protocolo de San José.

${ }^{44}$ Ídem.
} 
Una vez que la Comisión acepta la procedencia de la denuncia, solicitará información al gobierno del Estado implicado en la presunta violación, el cual deberá remitir lo solicitado en un plazo razonable, fijado por la propia Comisión. ${ }^{45}$ Pasado ese término, la Comisión verificará si todavía persiste la violación denunciada, en caso negativo, archivará el caso; si persistiere, buscará una solución amistosa entre los implicados. ${ }^{46}$

De no llegarse a una solución amistosa, la Comisión redactará un informe justificado, el cual será retransmitido a los implicados. ${ }^{47}$ Si en el plazo de tres meses a partir de la remisión del informe a los interesados, el asunto no ha sido solucionado o sometido a la decisión de la Corte Interamericana; la Comisión podrá emitir sus conclusiones, haciendo las recomendaciones que estime pertinentes y señalando un plazo para que el Estado las cumpla. ${ }^{48}$

En el supuesto de que el caso lo amerite, la Comisión lo podrá presentar ante la Corte a fin que ésta resuelva. ${ }^{49}$ Asimismo, es facultad exclusiva de la Corte el "conocer de cualquier caso relativo a la interpretación y aplicación de las disposiciones de esta Convención que le sea sometido, siempre que los Estados Partes en el caso hayan reconocido o reconozcan dicha competencia, ora por declaración especial, como se indica en los incisos anteriores, ora por convención especial." ${ }^{50}$

En todo caso, la Corte al resolver si hubo violación de un derecho o libertad contenida en la Convención, y en el caso en particular, de algún protocolo adicional; "dispondrá que se garantice al lesionado en el goce de su derecho o libertad conculcados. Dispondrá, asimismo, si ello fuera procedente, que se reparen las consecuencias de la medida o situación que ha configurado la vulneración de esos derechos y el pago de una justa indemnización a la parte lesionada."

Quedando reservada su facultad de imponer las medidas provisionales que estime pertinentes, cuando el caso conlleve una violación de extrema gravedad y urgencia, y cuando se haga necesario evitar daños irreparables a las personas. ${ }^{52}$

\section{CONCLUSIONES}

Lo que la doctrina nacional e internacional ha denominado "derechos económicos, culturales y sociales" cuentan con un contenido bastante amplio de derechos humanos, dentro de los que se encuentran los relacionados con el trabajo, la seguridad social, la

\footnotetext{
${ }^{45}$ Cfr. Artículo 48, primera parte, fracción a) del Protocolo de San José.

${ }^{46}$ Cfr. Artículo 48, primera parte, fracción f) del Protocolo de San José.

${ }^{47}$ Artículo 50 del Protocolo de San José.

${ }^{48}$ Artículo 5 I del Protocolo de San José.

${ }^{49}$ Artículo 6 I del Protocolo de San José

${ }^{50}$ Artículo 62, párrafo 3, del Protocolo de San José.

${ }^{51}$ Artículo 63, párrafo I, del Protocolo de San José.
} 
vida en familia, la participación en la vida cultural y los beneficios que ella trae consigo; el acceso a la vivienda; la adecuada alimentación; el derecho a la salud; el derecho a la educación; el derecho a un medio ambiente sano; y el derecho de la niñez, de los ancianos y de los minusválidos.

Los derechos humanos al tener un contenido contingente, pueden ampliarse $o$ disminuirse según las necesidades que requiera el conglomerado social. Lo cierto es que en la actualidad no existe un catálogo definido del contenido de este tipo de derechos humanos.

Puede establecerse una clara diferencia entre los términos de "derechos del hombre", "derechos humanos" y "derechos fundamentales". Siendo este último el más adecuado para el Derecho constitucional, pues hace referencia al derecho humano institucionalizado mediante normas de Derecho positivo.

En la historia del Derecho constitucional mexicano se hallan ejemplos claros y antiguos de derechos fundamentales. Sin embargo, un trazo es común en ellos: todos parten de la Declaración de los Derechos del Hombre y del Ciudadano de I789; y, por lo tanto, toda mención es a partir del siglo XIX.

El primer texto constitucional en contener un catálogo de derechos fundamentales, en cuanto tales, fueron las Bases Orgánicas de I843; aunque debido a su corta vigencia y a su poca aceptación, debe reconocerse a la Constitución Política de la República Mexicana de 1857, la mención de incorporar de manera fehaciente derechos fundamentales.

De la misma manera, fue esta Carta Magna la que adueñó una figura fundamental para el sistema jurídico mexicano: el juicio de amparo, mismo que se volvería a reflejar en la Constitución de 1917.

La actual constitución política destaca por ser la primera carta fundamental de contenido social en la historia universal, y si bien no fue hasta 1988 con la suscripción del Protocolo Adicional a la Convención Americana sobre Derechos Humanos en Materia de Derechos Económicos, Sociales y Culturales, conocido como el Protocolo de San Salvador; que se habló de un contenido de los derechos humanos de esta índole; el texto constitucional mexicano los reguló setenta años antes, y sobre todo, los garantizó mediante el juicio de amparo.

Actualmente en México los derechos económicos, sociales y culturales cuentan con una doble protección y una regulación complementaria. Por una parte, se encuentran en los derechos fundamentales que la Constitución actual reconoce; y por el otro, yacen en los tratados internacionales especializados en que el Estado mexicano es parte.

Su garantía se basa en el juicio de amparo, a nivel nacional, tanto para la protección de los derechos fundamentales como de los derechos humanos contenidos en los tratados internacionales. Además, se cuenta con el acceso a la justicia internacional, pues el Estado Mexicano reconoció la competencia jurisdiccional de la Corte Interamericana de Derechos Humanos. 


\section{2 ¿Cómo benefician los derechos humanos a la erradicación de la pobreza?}

Como se desprende, en México existen los derechos económicos, sociales y culturales desde la segunda mitad del siglo XIX. Tradicionalmente este tipo de derechos en México han sido ubicados en la rama jurídica denominada "Derecho social", modificando de esa manera la dualidad con la que VON SAVIGNY catalogaba a la ciencia jurídica. Dentro de esta nueva rama del Derecho, se suelen incorporar el Derecho del trabajo, el Derecho agrario, el Derecho a la seguridad social, el Derecho ambiental, el Derecho a la educación, etc.

Destaca esta rama jurídica por buscar brindar mayor protección a sectores históricamente desiguales. En México, esa salvaguarda va mucho más allá de generar leyes secundarias que regulen las relaciones entre grupos vulnerables; en materia adjetiva, es decir, procedimental, los trabajadores y a los campesinos gozan de mayores garantías, en específico, con la suplencia de la queja deficiente.

Esta figura viene a romper el principio de la igualdad procesal, pues cuando la parte agraviada proviene de un sector social (entiéndase trabajador, comunero o ejidatario), la ley le exime de formalismos rigurosos e impone la obligación al juzgador de asistirle y suplir la falta de conocimiento legal que pueda presentar. De esa forma, el Poder Legislativo consideró que la protección podría hacerse aún más efectiva.

El problema radica ya no en determinar si en México existen derechos humanos o no, pues es bien sabido que desde I 843 con las Bases Orgánicas se enlistan en el texto constitucional los derechos que los constituyentes han creído básicos. Ahora cabe analizar el impacto que su regulación ha tenido en México, y para ello, la única manera de realizarlo es mediante la estadística.

Debemos analizar indicadores históricos con tal de determinar si la regulación de los derechos fundamentales -otrora garantías individuales - ha brindado un verdadero progreso en el aspecto económico, social y cultural. Por ello, es indispensable estudiar los datos que muestren el estado social hasta antes de la Constitución de 1917, o lo que es lo mismo, el Porfiriato.

\section{a) El Porfiriato}

Como ya se indicó anteriormente, ${ }^{53}$ "El Porfiriato" es la denominación que la historiografía mexicana ha dado al periodo comprendido entre 1876, año de la publicación del Plan de Tuxtepec, y el año 1910, fecha en el que inicia la Revolución Mexicana; cuya nota distintiva es la dictadura que ejerció el general Porfirio Díaz Mori.

${ }^{53}$ Cfr. Supra punto II. 4. 
Para el análisis se utilizó como base el libro de Estadísticas sociales del Porfiriato. 1877-1910, publicado en 1956 por la entonces Dirección General de Estadística de la Secretaría de Economía.

Según esta recopilación, México en 1910 contaba con una población de 15, 160,377 habitantes; repartidos de manera muy diferente a la actualidad. El estado más poblado era Jalisco con I ,208,855 habitantes; le seguía Veracruz con I , I 32,859; Guanajuato con I,08I, 65 I; y Oaxaca con I,040,398. . $^{54}$

El estado menos poblado era el de Quintana Roo con una población de 9,109 personas; le seguía Baja California con 52,272; Colima con 77,704 y Campeche con $86,661 .{ }^{55}$

En el México de 1905 se registró el nacimiento de 461,56 I personas, dentro de los que 273,693 correspondieron a hijos legítimos. Por el contrario, se registraron 432,077 defunciones. ${ }^{57}$

Dentro de las causas de mortandad registradas en 1903, sobresale la diarrea (46 243), la neumonía $(38,860)$ y la tuberculosis $(12,945){ }^{58}$

Las políticas públicas encaminadas a la salud fueron de poco alcance, dado que de 1893 a 1907, sólo se vacunaron a 5,093, 149 personas. ${ }^{59}$

El México de inicios del siglo XX era un país bastante joven. De los 14,222,445 habitantes que tenía la república en 1907, 6, 170,606 tenían menos de quince años, es decir, el $43.39 \%$ del total. ${ }^{60}$

La mortalidad en menores de un año fue elevada en relación al número totales de nacimientos. En 1900 se registraron 142,264 defunciones de infantes menores a un año de edad; para 1903 se redujo a 119,657. ${ }^{61}$ No hay registro de los nacimientos registrados en el mismo año, sin embargo, si se toma en consideración una cifra aproximada a la cifra de 1905 (46 I ,56 I), se llega a la conclusión que de cuatro infantes, uno moría antes de cumplir el año de vida. Las principales causas de defunción de menores en 1903 eran la tos ferina ( I I,383), el paludismo $(8, \mid 46)$ y la viruela $\left(6,23\right.$ I). ${ }^{62}$

\footnotetext{
${ }^{54}$ Secretaría de Economía, Estadísticas sociales del Porfiriato. 1877 - 1910, Talleres Gráficos de la Nación, México 1956, n. I, p. 7 y8.

${ }^{55}$ Ídem.

${ }^{56}$ Hijos nacidos fuera de la relación matrimonial.

${ }^{57}$ Secretaría de Economía, op cit., n. 15, 17 y 18, p. 19 - 22.

${ }^{58}$ Ibídem, n. 22, p. 25.

${ }^{59}$ Ibídem, n. 25, p. 27.

${ }^{60}$ Ibídem, n. 26, p. 27.

${ }^{61}$ Ibídem, n. 28, p. 28.

${ }^{62}$ Ibídem, n. 29, p. 28. 
El presupuesto de egresos en 1910 fue de I 31 1,285,285 pesos a nivel federal, estatal y municipal; del total 12,804,220 fueron destinados a educación (9.75\%); 2,623,4l3 (2.00\%) a la asistencia y a la seguridad; y sólo 710,232 (0.54\%) a servicios de salud. ${ }^{63}$

Para 1910 existían 410,345 agricultores libres y 3, I 23,975 peones repartidos en sólo 830 haciendas. ${ }^{64}$

En 1907 sumaban un total de 12,068 escuelas primarias en todo el país ${ }^{65}$, en ellas 657,843 menores estudiaban, repartidos en 390,2 8 hombres y 267,625 mujeres. ${ }^{66}$ Tratándose de educación superior, en todo el país había diez escuelas técnicas, 26 escuelas normales ${ }^{67}$ y 21 universidades. ${ }^{68}$

De las escuelas existentes en México en el año de 1907, 586 eran sostenidas por el clero. ${ }^{69}$

Respecto a ciertos indicadores que muestran el acceso a la cultura, se tiene constancia de que en 1907, en todo el país sólo había 38 museos $^{70}$ y 187 bibliotecas $^{71}$. Existían 56 sociedades científicas en todo el país, concentrándose el mayor número en la Ciudad de México ( 13$)^{72}$; los periódicos contabilizaban la cifra de I,57 I a nivel nacional, liderando la capital del país con el mayor número de rotativos (394); ambas cifras del año de $1907 .{ }^{73}$

\section{b) México en la actualidad}

Tomando la cifra más reciente del reporte anterior ( 19 |0), a la fecha han pasado I I 7 años. En un siglo ocurren infinidad de acontecimientos, y en México no fue la excepción. La Revolución Mexicana provocó que los indicadores nacionales se descontrolaran. A la fecha no se sabe ni siquiera la cantidad de personas que fallecieron por el conflicto armado; la cifra más positiva calcula en un millón el número de defunciones en poco menos de diez años.

\footnotetext{
${ }^{63}$ Ibídem, n. 40, p. 36.

${ }^{64}$ Ibídem, n. 46, p. 40.

${ }^{65}$ Ibídem, n. 49, p. 42.

${ }^{66}$ ĺdem.

${ }^{67}$ La escuela normal era aquella "en que se hacían los estudios y la práctica necesarios para obtener el título de maestro de primera enseñanza". (Diccionario de la Real Academia de la Lengua Española, consultado el 16 de octubre del 2017 en www.rae.es). En México subsiste esta institución a la fecha.

${ }^{68}$ Secretaría de Economía, op cit., n. 52, p. 50.

${ }^{69}$ Ibídem, n. 53, p. 56.

${ }^{70}$ Ibídem, n. 57, p. 62.

${ }^{71}$ Ibídem, n. 58, p. 63.

${ }^{72}$ Ibídem, n. 59, p. 63.

${ }^{73}$ Ibídem, n. 60, p. 63.
} 
Con la promulgación de la Constitución Política de los Estados Unidos Mexicanos se ampliaron todos los derechos fundamentales reconocidos en la antigua Carta Magna, y se añadieron otros no previstos en ella, en especial en materia agraria y laboral.

Los latifundios dejaron de existir y sus tierras fueron repartidas entre los campesinos para conformar ejidos, y entre indígenas creándose comunidades.

La protección a aquellos grupos vulnerables que gestaron la lucha armada se hizo realidad. A las grandes empresas que se encontraban en territorio nacional se les obligó a dar prestaciones de vivienda y escuela para sus trabajadores.

La mejora en las condiciones agrarias y laborales significó un aumento en la producción nacional, que vería su máximo esplendor en los finales de la década de los años treinta y principios de los cuarenta. En esa época, en virtud de la guerra mundial que asolaba el planeta, los países exportadores de materias primas, como fue el caso de Latinoamérica, se vieron con tasas de crecimiento nunca antes vistas en la región.

Una vez terminada la guerra, los gobiernos latinoamericanos solicitaron a la Comisión Económica para América Latina (CEPAL) "la constitución de dos grupos de expertos, uno para el establecimiento gradual de un régimen de pagos multilaterales y otro para definir las características del mercado regional."

En el informe emitido de la Secretaría Ejecutiva de la CEPAL se llegó a la conclusión que el crecimiento acelerado latinoamericano no sería posible a pesar de que toda la región se industrializase. No por ello debía dejarse de lado como política rectora de todos los Estados, pues aquello que frenaba ese incremento era la idea de realizarlo en mercados nacionales cerrados.

De tal suerte que Raúl Prebisch, director principal de la Secretaría Ejecutiva de la CEPAL, afirmó: "No veo otra solución fundamental de este grave problema y al del costo elevado del proceso sustitutivo, que romper ese molde anacrónico mediante la formación gradual y progresiva del mercado común y la consiguiente diversificación de importaciones y exportaciones."

Así la CEPAL propuso la creación de una zona de libre comercio mediante la eliminación de los aranceles de los bienes esenciales de la región, para comenzar un verdadero proceso de integración de América Latina.

A partir de entonces se ha buscado integrar a la región latinoamericana, no sólo en términos comerciales, sino en términos propiamente jurídicos; ambas finalidades representadas en la actual Asociación Latinoamericana de Integración (ALADI) y en el Sistema Interamericano de Derechos Humanos, respectivamente.

Comparar las situaciones habidas en el México de inicios del siglo $X X$ con los indicadores actuales resulta una barbaridad. Las condiciones sociales se han transformado bastante, y esos cambios son fiel espejo de la idea social que sobrevivió a la Revolución.

Lo cierto es que al día de hoy en México se vive un nuevo cambio paradigmático respecto a las políticas sociales. El Estado social de Derecho que triunfó con la Constitución de 1917 parece quedar rezagado ante las nuevas necesidades que exige un mundo más globalizado. 
La Constitución ha sido reformada múltiples veces para adecuar a nuestra sociedad y participar de un mundo sin fronteras. En el texto constitucional original se vetaba a los extranjeros adquirir tierras en ciertas zonas; se estipulaba que todos los bienes pertenecían originariamente a la Nación y sólo ella podía explotar las reservas naturales, en específico los hidrocarburos; se daba facultades al Ejecutivo federal para poder expulsar a cualquier ciudadano extranjero que considerara pernicioso sin ningún otro requerimiento; etc.

Disposiciones que podrían frenar, sin duda, una economía que ha pasado ya de la intermediación de bienes a esencialmente de servicios. Ese cambio del poder político al económico no ha debilitado las garantías sociales que la Constitución de 1917 generó, todo lo contrario, las ha fortalecido. El Derecho se ha convertido en México en un verdadero ideal de justicia, por lo que es entendible la exigencia de la sociedad de que existan tribunales autónomos y transparentes, y un sistema que garantice esos principios.

Sin duda las garantías sociales contempladas en nuestra Constitución han servido para generar un cambio económico, social y cultural en México. No obstante, hay un aspecto que resalta en cuanto a la medición de la pobreza: la dificultad de definirla.

La definición del término es bastante compleja, pues varía de país en país, de cultura en cultura y de región en región. No existe propiamente una definición unívoca sobre pobreza.

Hay cinco hallazgos principales: Primero, muchos factores convergen en hacer a la pobreza un fenómeno complejo y multidimensional. Segundo, como se esperaba, la pobreza es definida rutinariamente como la falta de lo que es necesario para el bienestar material, especialmente los alimentos, aunque también la vivienda, la tierra y otros bienes. La pobreza es la falta de múltiples recursos que llevan a la privación física. Tercero, la definición de pobreza de la gente revela importantes aspectos psicológicos sobre ésta. La gente pobre es extremadamente consciente de su falta de voz, de poder e independencia, que la pone en situación de explotación. Su pobreza también los hace vulnerables a la grosería, humillación y trato inhumano tanto por agentes públicos como privados de quienes procuran ayuda. La gente pobre también habla acerca del dolor que conlleva la inevitable violación de normas sociales y la incapacidad de mantener su identidad cultural mediante la participación en tradiciones, festivales y rituales. Su incapacidad de participar plenamente en la vida comunitaria lleva a un colapso de las relaciones sociales. Cuarto, la ausencia de infraestructura básica

\footnotetext{
${ }^{75}$ Narayan, Deepa, A review of World Bank participatory poverty asessments: consultations with the poor, Banco Mundial, 1999, p. 26.
} 
-particularmente caminos, transportes, agua y servicios de salud-emergen de forma crítica. (...) Finalmente, los pobres se centran en los bienes en lugar de los ingresos y relacionan su falta de recursos físicos, humanos, sociales y ambientales con su vulnerabilidad y exposición al riesgo. ${ }^{74}$

En el caso mexicano, el INEGI señala que

Una persona se encuentra en situación de pobreza cuando tiene al menos una carencia social (en los seis indicadores de rezago educativo, acceso a servicios de salud, acceso a la seguridad social, calidad y espacios de la vivienda, servicios básicos en la vivienda y acceso a la alimentación) y su ingreso es insuficiente para adquirir los bienes y servicios que requiere para satisfacer sus necesidades alimentarias y no alimentarias. ${ }^{75}$

De esa forma el umbral de pobreza lo impone nuestra propia constitución. El Estado mexicano desde 1917 se ha comprometido a prestar servicios catalogados por él mismo como básicos, y ante cualquier carencia en la implementación de éstos surge la pobreza.

Por ello, puede afirmarse que hablar de pobreza en México no es exacto, y por esa razón nuestro país siendo en indicadores pobre, tiene un índice de desarrollo humano alto.

Debe tenerse en consideración la relación proporcional entre la carencia de derechos y la pobreza, aunque ello no es exacto. La positividad de los derechos humanos no parece tener relación directa con los índices de pobreza o prosperidad de una sociedad. Confróntese el caso de Canadá, cuya constitución reconoció los derechos humanos hasta 1982, y no por ello se recuerda atentados terribles contra la dignidad humana en aquellas latitudes.

En sociedades tan desiguales como las latinoamericanas parece más que necesario el reconocimiento que los textos constitucionales hagan de los derechos humanos; pues sirven para la sociedad de guía y recordatorio de lo mínimo, y sobre todo, de que ello debe ser proporcionado por el mismo Estado, o por lo menos, en el particular caso del mexicano.

\section{REFERENCIAS}

CARBONELL SÁNCHEZ, Miguel. Los derechos fundamentales en México. México: Editorial Porrúa, 2009.

CALZADAPADRÓN, Feliciano. Derecho constitucional. México: Editorial Porrúa, 2009.

CASTAÑEDA, Mireya. La protección no jurisdiccional de los derechos humanos en México. Colección de textos sobre derechos humanos, Comisión Nacional de los Derechos Humanos, México 2015. 
Encuesta Intercensal del 20/5, consultada en http://www.beta.inegi.org.mx/proyectos/ enchogares/especiales/intercensal/default.html

Encuesta Nacional en Viviendas, Consulta Mitofsky, octubre del 2016, consultado en http://www. consulta.mx/index. php/estudios-e-investigaciones/mexicoopina/item/884-mexico-confianza-en-instituciones-2016 el día 29 de septiembre del 2017.

FERNÁNDEZ FERNÁNDEZ, Vicente. "El juicio de amparo: historia y futuro de la protección constitucional en México", Revista IUS, vol. 5, n. 27, Instituto de Ciencias Jurídicas de Puebla, Departamento de Investigaciones, Puebla enero-junio, 201 I .

Documentos básicos de derechos humanos en el sistema interamericano. Introducción, consultado en http://www.oas.org/es/cidh/mandato/documentos_basicos.asp, el día I de agosto del 2017.

NARAYAN, Deepa. A review of World Bank participatory poverty asessments: consultations with the poor, Banco Mundial, 1999.

Panorama general. Informe sobre desarrollo humano 20 16. Desarrollo humano para todos, Programa de las Naciones Unidas para el Desarrollo, Nueva York 2016.

Preguntas frecuentes sobre los derechos económicos, sociales y culturales, Boletín Informativo n. 33, Organización de las Naciones Unidas, Ginebra, Suiza.

Secretaría de Economía, Estadísticas sociales del Porfiriato. 1877 - 1910, Talleres Gráficos de la Nación, México 1956.

Transparencia internacional en www.transparency.org

Recebido em: 03/1 I/2017

Aprovado em: I I/12/2017 
